NBER WORKING PAPER SERIES

\title{
CYCLING TO SCHOOL: \\ INCREASING SECONDARY SCHOOL ENROLLMENT FOR GIRLS IN INDIA
}

\author{
Karthik Muralidharan \\ Nishith Prakash \\ Working Paper 19305 \\ http://www.nber.org/papers/w19305 \\ NATIONAL BUREAU OF ECONOMIC RESEARCH \\ 1050 Massachusetts Avenue \\ Cambridge, MA 02138
}

August 2013

\begin{abstract}
This project greatly benefited from financial and logistical support from the International Growth Center (IGC) for the research as well as its dissemination. We also thank the Department of Education, Government of Bihar for support with the data collection. We are especially grateful to Andrew Foster for his suggestions on this paper. We further thank Harold Alderman, Kate Antonovics, Mehtabul Azam, Chris Barrett, Eli Berman, Sonia Bhalotra, Prashant Bharadwaj, Aimee Chin, Jeff Clemens, Julie Cullen, Gordon Dahl, Jishnu Das, Eric Edmonds, Delia Furtado, Maitreesh Ghatak, Roger Gordon, Shaibal Gupta, Gordon Hanson, Edward Hoang, Scott Imberman, Chinhui Juhn, Santosh Kumar, Anjan Mukherji, Paul Niehaus, Emily Oster, Marc Rockmore, Andres Santos, Abhirup Sarkar, and various seminar participants for helpful comments and suggestions. Jay Prakash Agarwal, Abhishek K.Choudhary, Elizabeth Kaletski, and Michael Levere provided excellent research assistance. The views expressed herein are those of the authors and do not necessarily reflect the views of the National Bureau of Economic Research.
\end{abstract}

NBER working papers are circulated for discussion and comment purposes. They have not been peerreviewed or been subject to the review by the NBER Board of Directors that accompanies official NBER publications.

(C) 2013 by Karthik Muralidharan and Nishith Prakash. All rights reserved. Short sections of text, not to exceed two paragraphs, may be quoted without explicit permission provided that full credit, including (C) notice, is given to the source. 
Cycling to School: Increasing Secondary School Enrollment for Girls in India

Karthik Muralidharan and Nishith Prakash

NBER Working Paper No. 19305

August 2013

JEL No. I21,I25,J16,O15

\begin{abstract}
$\underline{\text { ABSTRACT }}$
We study the impact of an innovative program in the Indian state of Bihar that aimed to reduce the gender gap in secondary school enrollment by providing girls who continued to secondary school with a bicycle that would improve access to school. Using data from a large representative household survey, we employ a triple difference approach (using boys and the neighboring state of Jharkhand as comparison groups) and find that being in a cohort that was exposed to the Cycle program increased girls' age-appropriate enrollment in secondary school by $30 \%$ and also reduced the gender gap in age-appropriate secondary school enrollment by $40 \%$. Parametric and non-parametric decompositions of the triple-difference estimate as a function of distance to the nearest secondary school show that the increases in enrollment mostly took place in villages where the nearest secondary school was further away, suggesting that the mechanism for program impact was the reduction in the time and safety cost of school attendance made possible by the bicycle. We find that the Cycle program was much more cost effective at increasing girls' enrolment than comparable conditional cash transfer programs in South Asia, suggesting that the coordinated provision of bicycles to girls may have generated externalities beyond the cash value of the program, including improved safety from girls cycling to school in groups, and changes in patriarchal social norms that proscribed female mobility outside the village, which inhibited female secondary school participation.
\end{abstract}

Karthik Muralidharan

Department of Economics, 0508

University of California, San Diego

9500 Gilman Drive

La Jolla, CA 92093-0508

and NBER

kamurali@ucsd.edu

Nishith Prakash

University of Connecticut

331 Oak Hall

Department of Economics

365 Fairfield Way, U-1063

Storrs, CT 06269-1063

nishith.prakash@uconn.edu 
"Investment in girls' education may well be the highest-return investment available in the developing world."

Lawrence H. Summers (while Chief Economist of the World Bank)

"I think the bicycle has done more to emancipate women than anything else in the world."

Susan B. Anthony (19 ${ }^{\text {th }}$ century leader of US women's suffrage movement)

\section{Introduction}

Reducing gender gaps in school enrollment has been one of the most important goals for international education policy over the past decade, and has been enshrined as one of the United Nation's Millennium Development Goals. ${ }^{1}$ While considerable progress has been made in reducing gender gaps in primary schooling, there continue to be significant gaps in secondary schooling, with a noticeable increase in adolescent years (Figure 1 - Panel A). It is therefore of substantial policy interest to identify cost-effective and scalable strategies for increasing secondary school enrollment and completion rates for girls in developing countries.

Policies to improve female education attainment in developing countries have focused on both increasing the immediate benefits of schooling to families as well as on reducing the costs of attending school. The most prominent category of demand-side interventions have been conditional cash transfers (CCT's) to households for keeping girls enrolled in school. Several well-identified studies of CCT programs have found a positive impact on girls' school enrollment and attainment (Fiszbein and Schady 2009). ${ }^{2}$ However, they have not been a very cost effective way of improving school attainment, perhaps because their main purpose was to provide income support to the poor and not only to increase schooling (Dhaliwal et al. 2012; Pritchett 2012).

On the supply side, the most common policy measure has been to improve school access by constructing more schools and thereby reducing the distance cost of attending school. While well-identified studies of the impact of school construction programs have found positive effects

\footnotetext{
${ }^{1}$ This policy priority is supported both on intrinsic grounds following the capabilities framework (Sen 1993, Nussbaum 2011) as well as on instrumental grounds following a vast body of prior research showing the benefits of increasing female education rates on several outcomes including lower infant, child, and maternal mortality; improved human capital transmission to children; and greater female labor force participation and income generation capacity. The World Development Report 2012 on "Gender Equality and Development" (World Bank 2011) summarizes the latest research on progress towards and benefits of gender equality.

${ }^{2}$ There is a vast literature on the impact of CCT programs on education, health, and other outcomes in developing countries. Some specific references include Schultz (2004), de Janvry et al. (2006), Filmer and Schady (2011), and Baird et al. (2011). Fiszbein \& Schady (2009) provide a good review of this literature.
} 
on enrollment (Duflo 2001, Burde and Linden 2013, Kazianga et al. 2013), there is a trade-off between school access and scale, which may be particularly relevant to secondary schools because they need qualified teachers for more subjects, and fixed infrastructure like laboratories, which require a minimum scale to be cost effective. Thus, while improving school access has proven to be effective at increasing school participation, it is not obvious that improving access should always take the form of constructing new schools.

In this paper, we evaluate the impact of an innovative program introduced by the Government of the Indian state of Bihar in 2006 that aimed to improve school access without additional school construction. The program provided all girls who enrolled in grade 9 with funds to buy a bicycle to make it easier to access schools. The 'Cycle program' was therefore a 'conditional kind transfer' (CKT) and had features of both demand and supply-side interventions. The enrollment conditionality is analogous to demand-side CCT programs, while the bicycle mimics the characteristics of a supply-side intervention by reducing the time, distance, and safety cost of attending school. The program has proven to be politically popular and has been replicated in other states across India, but there has been no credible estimation of its impact.

The main challenge for identification of program impact is that it was launched across the full state of Bihar at a time of high growth, and plausibly increasing rates of return to education. Thus, the large increases in girls' enrollment during this period (which policy makers cite as evidence of positive impact) could simply reflect broader trends and not be in any way caused by the Cycle program. There is also a risk of over-reporting of girls' enrollment in administrative data in response to the Cycle program and the additional funds associated with it. ${ }^{3}$ Thus, an important reason to worry that the program may have had no real impact is simply the possibility of corruption in implementation, and manipulation of administrative records.

We address both these concerns (identification, and reliability of school-level data) by employing a triple and quadruple difference strategy using a large household survey conducted in 2007-08 (during the second year of the Cycle program) that included detailed household roster data with the education history of all residents. We follow Duflo (2001) and treat older cohorts (aged 16 and 17) who were not exposed to the program when they were making the transition to

\footnotetext{
${ }^{3}$ Distorting school records in response to incentives is not uncommon in India, and has also been documented in other settings such as school feeding programs in India (Linden and Shastry 2012).
} 
secondary school as the control group and younger cohorts (aged 14 and 15) who were exposed to the program during this transition as the treatment group. The key dependent variable of interest is whether a child is enrolled in or has completed grade 9, and we start our analysis by comparing this outcome across girls in treated and untreated cohorts (first difference).

We address the majority of omitted variable concerns (including economic growth and investments in school quality) by comparing the changes in girls' enrollment to the changes in boys' enrollment for the same cohorts (as in Jayachandran and Lleras-Muney 2008). However, treating this double-difference estimate as causal would require that there were parallel trends in boys' and girls' enrollment prior to the program. Since we reject the parallel trend assumption, we compare the double difference estimate in the state of Bihar (the treated state), with the same estimate for the state of Jharkhand, which is a neighboring state which was a part of the state of Bihar for over 50 years, and only separated administratively in 2001. This triple difference is our preferred estimate of program impact (since we do not reject the parallel trends assumption).

Our main result is that being in a cohort exposed to the Cycle program increased the probability of a girl aged 14 or 15 being enrolled in or having completed grade 9 by 30\% (a 5.2 percentage point increase on a base age-appropriate enrollment rate of 17.2 percent). Further, the program also bridged the pre-existing gender gap in age-appropriate secondary school enrollment between boys and girls (of 13 percentage points) by $40 \%$. However, while the reduced-form triple difference estimate can plausibly be attributed to the Cycle program, we still cannot rule out the possibility that this estimate is confounded by other factors that changed at the same time (such as differential trends in returns to education for girls across the states).

We address this issue by noting that if the mechanism of program impact was that the bicycle reduced the 'distance cost' of school attendance, we should find a differential impact on girls' secondary school enrollment as a function of the initial distance to a secondary school. We construct a quadruple difference estimate of program effectiveness by comparing the triple difference estimate across villages above and below the median distance to a secondary school $(3 \mathrm{~km})$, and find that almost all the program impacts are found in villages that are over 3km away from a secondary school. We also plot the triple difference non-parametrically as a function of distance to the nearest secondary school, and find that the treatment effect has an inverted-U shape. This is exactly what would be expected from a model where the cycle reduces costs of 
schooling proportional to the distance to school (but where the absolute cost of attendance is still too high to attend at very large distances).

This is our most important result, because the inverted-U pattern of the treatment effect as a function of distance to a secondary school is unlikely to be explained by potentially omitted variables. ${ }^{4}$ Further, our finding close to zero impacts on enrollment for girls who lived near a secondary school suggest that the magnitude of the triple difference estimate is not confounded by omitted variables such as differential changes in returns to education for girls in Bihar in the same time period. This result also suggests that the main mechanism of program impact was not the conditionality, but rather the reduction of the distance cost of attending school.

We also study the impact of the program on learning outcomes by collecting official data on student performance on the secondary school certificate (SSC) exam in both Bihar and Jharkhand. We find that in cohorts exposed to the Cycle program, the number of girls appearing for the SSC exam increased by 9.5\%, but find no impact on the number of girls who passed the exam. These results suggest that exposure to the Cycle program not only increased enrollment on paper, but also increased the number of girls who stayed in secondary school to the point of being able to take the high-stakes SSC exam. However, the lack of any impact on the number of girls who passed the exam suggests that the increase in enrollments may not have translated into learning improvements, and is consistent with evidence on conditional cash transfer programs from around the world that find significant impacts on enrollment but not on achievement.

We find that the Cycle program was considerably more cost effective in increasing female school enrollment compared to a conditional cash transfer program in Pakistan, suggesting that this was a setting where an in-kind transfer of the cycle may have been more effective than an equivalent conditional cash transfer. Possible reasons include: (a) the cycle directly contributed to reducing the daily cost of school attendance - unlike cash transfers, (b) spending on the cycle (which was not infra-marginal to initial household spending) made it more likely that the entire transfer would 'stick' to the targeted girl as opposed to simply augmenting the household budget, where the girl would have only received a share of this transfer equal to her Pareto weight in the

\footnotetext{
${ }^{4}$ One further concern could be that other complementary investments such as improvements in roads, and law and order may also differentially benefit girls as a function of distance to school and thereby generate the same pattern. We address this concern by conducting a placebo test on the enrollment of eighth-grade girls (who are just one year younger, but were not eligible for the Cycle program), and find no effect here. See section 5.1 for details.
} 
household, and (c) the coordinated provision of cycles to all eligible girls may have generated positive externalities including increased safety from girls cycling to school in groups, and a relaxation of patriarchal social norms against post-adolescence female education (especially when attending secondary school would require traveling outside the village). We discuss these issues in detail in section 6, along with a discussion of ways in which the Cycle program may have contributed to female empowerment in the patriarchal setting of rural Bihar, along the lines of the quote from Susan Anthony regarding the $19^{\text {th }}$ century United States.

From a policy perspective, it is worth highlighting that we evaluate an 'as is' implementation of a program that was scaled up across a state with over 100 million people, and a history of high levels of corruption in public programs. The Cycle program also had important features that enabled it to be implemented remarkably effectively (we discuss these features in the conclusion), with leakage rates as low as 3\% (Ghatak et al. 2013). Thus the Cycle program appears to have been quite unique in its ability to effectively provide a non-fungible transfer to girls that was not captured by either households or officials, and which thereby reduced the daily cost of school attendance for girls. The strikingly large positive effects of the Cycle program on increasing female secondary school enrollment and in reducing the gender gap, its relative ease of implementation, its high visibility, and its political popularity suggest that this may be an especially promising policy to scale up in other developing country settings as well.

Methodologically, our approach illustrates the feasibility of credible impact evaluations even in contexts of universal program roll out. Specifically, the analysis of differential impact of the Cycle program as a function of distance to a secondary school is similar to the approaches employed in Bleakley (2007) and Hornbeck (2010) in historical contexts where pre-existing cross-sectional heterogeneity is used to predict differential 'effective impact' of a universally implemented program (de-worming) or broadly available new technology (barbed wire). Chetty et al (2013) use a similar approach to estimate the impact of the EITC on earnings in the US.

The rest of this paper is organized as follows. Section 2 describes the context and the program; section 3 describes the data, estimating equations, and identification assumptions; section 4 presents the main results and discusses heterogeneity; section 5 presents robustness checks, while section 6 discusses cost effectiveness and the broader implications of our results for debates on cash versus kind transfers and gender empowerment; section 7 concludes. 


\section{Context and Program Description}

Bihar is the third most populous state in India, with a population of over 100 million. At the turn of the century, Bihar was one of the most economically backward states of India and also had among the lowest mean levels of education (India Human Development Survey 2005). In addition, the gender gap in educational attainment is even more pronounced in Bihar relative to the all India figures (Figure 1 - Panel A). The drop off in girls' enrollment is particularly pronounced at ages 14 to 15, which is around the age of menarche and also the age of transition to secondary schooling. An important barrier to secondary school enrollment is the greater distance to a secondary school relative to the distance to a primary school and the probability of 14 and 15 year olds being enrolled in school steadily declines as the distance to the nearest secondary school increases (Figure 1 - Panel B).

While the central and state governments in India have succeeded in expanding access to primary schools to the point where over $95 \%$ of villages have a primary school, access to secondary schools is considerably more limited. Figure 2 plots a histogram of villages in a representative sample of Bihar and Jharkhand by their distance to a secondary school, and we see that over $50 \%$ of villages are at least three kilometers away from the nearest secondary school. While there is an ongoing national campaign to expand access to secondary schooling via school construction and expansion, ${ }^{5}$ this is an expensive and ongoing process and can only slowly reach children who are currently far from a secondary school.

Following over a decade of weak performance on several measures of governance and human development, the newly elected state government in Bihar (in late 2005) prioritized improvements in law and order, and service delivery in the social sector and undertook several initiatives to improve education (Chakrabarti 2013). A particularly prominent program that the Government of Bihar (GoB) launched in 2006 was the Chief Minister's Bicycle program (hereafter referred to as the Cycle program) that provided girls who enrolled in secondary school (grade 9) with a free bicycle. This was a highly visible program that had the personal backing of the Chief Minister (the elected head of the state government), and provided Rs. 2,000 ( \$40) to every eligible female student to purchase a bicycle (later raised to Rs. 2,500 or $\sim \$ 50$ ).

\footnotetext{
${ }^{5}$ This is the "National Campaign for Secondary Schooling", known as the Rashtriya Madhyamik Shiksha Abhiyan (often abbreviated as RMSA).
} 
The government did not directly procure the bicycles, but distributed the funds to eligible girls through their schools (in public ceremonies attended by local officials as well as elected representatives), and required the school principal to collect the receipts and provide a utilization certificate showing that the funds were used to purchase a bicycle. Households therefore had some flexibility in the specific type of bicycle they bought, but the program was explicitly designed to be a conditional kind transfer (CKT) of a bicycle to be used by the eligible girl, as opposed to the more typical conditional cash transfer (CCT) programs used to reward parents and households for sending their daughters to school. In particular, since few households would have purchased cycles for girls, the cycle would not be infra-marginal for the typical household. Thus, a key distinction between this program and typical CT programs was that the transfer provided under the Cycle program would be more likely to be spent directly on the girl whose enrollment and attendance was targeted as opposed to simply augmenting the household budget. ${ }^{6}$

While well-intentioned, it was far from obvious that the program would have any meaningful impact. In addition to having poor indicators of human development, Bihar also had very poor indicators of service delivery. A nationally-representative study conducted in 2003 found that Bihar had the second-highest rate of teacher absence among states in India, with close to $38 \%$ of teachers on the payroll not being found in school during working hours (Kremer et al. 2005). In a completely different sector (food security), estimates by the Planning Commission of India in 2005 found that Bihar had the highest rates of leakage (exceeding 75\%) in the Targeted Public Distribution System (TPDS) which is the flagship program of the Government of India for improving food security for the poor (PEO 2005).

Thus, while the need for additional resources for meeting the education MDGs was among the highest in Bihar, weaknesses in governance and service delivery also meant that the additional spending may have been less likely to translate into improved outcomes in such a context. In the case of the Cycle program, mechanisms for non-impact could include (a) inflation of official records of enrollment by head-teachers and, (b) parents taking the money for the cycle and providing fake receipts showing bicycle purchase. At an even more basic level,

\footnotetext{
${ }^{6}$ Of course, the bicycle could be sold and converted to cash, but qualitative interviews suggest that the public ceremonies for the provision of the funds for the bicycle significantly increased the social cost of doing so (see Ghatak, Kumar, and Mitra 2013 for more details on program implementation). The large increase in the number of cycles in circulation due to the program could also be expected to reduce the price of used cycles.
} 
lags in delivering funds to schools and beneficiaries may have led to limited effectiveness of the Cycle program in its stated aim of improving secondary school enrollment of girls.

\section{Data, Identification Strategy, and Estimating Equations}

\subsection{Data}

The main source of data for our analysis is the third wave of the District Level Health Survey (DLHS-3) in India which was conducted in 2007-08. The DLHS uses a nationally representative sample of households and is one of the largest demographic and health surveys ever carried out in India. The total sample size is around 720,000 households across 601 districts in India, with a mean sample size of 1,200 households per district. The household questionnaire in the DLHS includes a roster of all members residing in the household, their education attainment, and current schooling status. It also includes detailed questions on the demographic and socioeconomic characteristics of the household. In addition, the village-level questionnaire in the DLHS includes information on all educational facilities available in the village, and the distance to the nearest educational facility of each type that is not available in the village (including primary schools, secondary schools, and institutions of higher education).

The timing of the DLHS-3 is especially appropriate for our analysis. The survey was conducted approximately 18 months after the Cycle program was launched. ${ }^{7}$ Since the typical age at which students enter grade nine (the first year of secondary school) is 14 or 15, household members who are 16 or 17 years old would not have been exposed to the program when they were of the age to decide on whether to continue to secondary school, while those who are currently 14 or 15 would have been eligible for the program. This enables us to treat 14-15 year olds as 'treated' cohorts and 16-17 year olds as 'control' cohorts. Our final estimation sample uses households that have at least one member aged 14 to 17 living in the states of Bihar and Jharkhand . Summary statistics of the estimation sample are in Table 1.

In addition to the DLHS data, we use two other data sets in this paper. First, we collect official secondary school enrollment data by gender for both Bihar and Jharkhand. We do not use this data for estimating treatment effects (since it is possible that the official enrollment data

\footnotetext{
${ }^{7}$ The program was launched in the school year 2006-07 (which started in June 2006), while the DLHS was conducted in late 2007 and early 2008.
} 
were manipulated in response to the program), but we do use this data from the years prior to the launch of the program (2002 to 2006) to test for parallel trends in the growth rate of enrollment of boys and girls in Bihar and Jharkhand. Second, to study the impact of exposure to the Cycle program on learning outcomes, we collect official data on the number of students who appeared in and passed the secondary school exit examination (known as the tenth-grade 'board' exam) in both Bihar and Jharkhand. This is a high-stakes exam that is the first externally graded exam in the Indian school system and the marks received on this exam are perhaps the most credible signal of human capital in the Indian school system at the age of sixteen. ${ }^{8}$

\subsection{Identification Strategy and Estimating Equations}

\subsubsection{Difference in Differences Estimate (DD)}

Our main outcome of interest is whether a student is enrolled in or has completed grade nine (the first year of secondary school). The first difference compares this outcome across girls aged 14 or 15 in Bihar (the 'treated' cohort) and girls aged 16 or 17 in Bihar (the 'control' cohort). Since this difference is clearly confounded by the several other changes taking place in Bihar during the same period, we use boys of the same ages in Bihar as a control group. As in Jayachandran and Lleras-Muney (2009), boys serve as an especially useful control group for the Cycle program, because they would have been exposed to all the other changes that were taking place in Bihar during the period of interest (including increasing household incomes and increased public investment in education), but were not eligible for this program.

The "Difference in Difference" impact of exposure to the program is estimated by:

$$
y_{i h v}=\beta_{0}+\beta_{1} \cdot F_{i h v} \cdot T_{i h v}+\beta_{2} \cdot F_{i h v}+\beta_{3} \cdot T_{i h v}+\varepsilon_{i h v}
$$

where $y_{i h v}$ is the outcome variable of interest corresponding to child $i$, in household $h$ and village $v . F_{i h v}$ is an indicator for being female, and $T_{i h v}$ is an indicator for being in a 'treated' cohort (being aged 14 or 15). The estimation sample includes all members of the household

\footnotetext{
${ }^{8}$ These exams are equivalent to the British O-Levels or GCSE examinations. Estimates of returns to education in India typically find convex returns to school education, with the returns to secondary schooling being higher than those to primary and middle school education (see Aslam et al. 2011). One possible explanation for this result is that years of primary schooling are not a very accurate indicator of human capital in an environment that practices 'automatic promotion' to the next grade regardless of actual level of academic performance. Thus, completing secondary education (by passing the tenth-grade exam) may be an especially important signal of human capital.
} 
roster in surveyed households aged 14 to 17, and the omitted category of 16 and 17 year olds correspond to the 'control' cohorts. $\beta_{1}$ is the DD estimate of the impact of being exposed to the Cycle program on being enrolled in or having completed grade nine. All standard errors are clustered at the village-level.

Since the growth rate of girls' enrollment could vary by household and village characteristics, we progressively augment (1) with controls for household demographics (caste and religion), socio-economic status (parental education, poverty status, and ownership of assets), and for village characteristics (including population and proximity to various facilities). In addition to accounting for differential growth rates, including the controls increases the precision on our estimates of interest by reducing the residual variation to be explained, and our preferred estimates therefore are the ones that include a full set of village and household controls (though we show the estimates without these controls as well).

\subsubsection{Triple Difference Estimate (DDD)}

The main challenge to interpreting $\beta_{1}$ in (1) as the causal impact of the Cycle program is that there may have been different trends in boys' and girls' secondary school enrollment during this period (which we show to be true). We therefore construct a 'triple difference' (DDD) estimate of program impact by comparing the double difference (as computed above) in the state of Bihar with the same double difference in the neighboring state of Jharkhand (which did not have the Cycle program). The use of Jharkhand as a comparison group for Bihar is especially credible since the two states were part of the unified state of Bihar until 2001 and were only administratively bifurcated into two states in 2001. Thus, the governance structure of the two states was identical until 2001, and the quality of governance in the two states was similar for some time after the bifurcation (for instance, Kremer et al. 2005 show that Bihar and Jharkhand had the second highest and highest rates of teacher absence across 19 Indian states in 2003).

The triple-difference estimate of exposure to the Cycle program is estimated by:

$$
\begin{aligned}
& y_{i h v}=\beta_{0}+\beta_{1} \cdot F_{i h v} \cdot T_{i h v} \cdot B H+\beta_{2} \cdot F_{i h v} \cdot B H+\beta_{3} \cdot T_{i h v} \cdot B H+\beta_{4} \cdot F_{i h v} \cdot T_{i h v}+\beta_{5} \\
& F_{i h v}+\beta_{6} \cdot T_{i h v}+\beta_{7} \cdot B H_{i h v}+\varepsilon_{i h v}
\end{aligned}
$$


where all the variables are defined as in (1), and $B H$ is an indicator for an observation from Bihar. The main parameter of interest is $\beta_{1}$ (the triple-difference estimate), and $\beta_{2}$ through $\beta_{7}$ are the estimates of the double interaction terms and linear terms respectively. The estimation sample is as in (1) but also includes Jharkhand. Standard errors are clustered at the village-level.

Table 1 shows the summary statistics of this estimation sample, and we see that there are some significant differences between Bihar and Jharkhand - especially in terms of caste and tribe composition, with the latter having a much larger share of the tribal population. We account for these differences by estimating (2) with a progressively richer set of controls for demographic, socioeconomic, and village characteristics. We show $\beta_{1}$ in each of these specifications, but focus our discussion on the specifications with the full set of village and household controls.

\subsubsection{Quadruple Difference Estimate}

As we discuss in section 4.1, we believe that the triple-difference estimate with controls for village and household characteristics provides an unbiased reduced form estimate of the impact of exposure to the Cycle program. Nevertheless, this estimate may be confounded by omitted variables that differentially affect the trend in girls' secondary school enrollment in Bihar (such as differential trends in returns to education for girls in Bihar). Further, it is also interesting to examine the extent to which the impact of the program (if any) can be attributed to the conditionality versus the reduction in the distance cost of attending school.

We address this issue by noting that if the mechanism of the impact of the Cycle program is that it improved school access by reducing the 'distance cost' of school, we should expect to see heterogeneous effects of the program as a function of the distance to the nearest secondary school, with smaller effects in cases where the secondary school was nearby. We see in Figure 2 that the median village in our sample was 3 kilometers away from a secondary school (both with and without population weights). We therefore define an indicator variable $L D_{v}$ ('Long Distance') that takes the value 1 if a village is 3 kilometers or further away from a secondary school, and estimate a quadruple difference using the specification:

$$
\begin{gathered}
y_{i h v}=\beta_{0}+\beta_{1} \cdot F_{i h v} \cdot T_{i h v} \cdot B H \cdot L D_{v}+\sum_{2}^{5} \beta_{i} \cdot(4 \text { Triple Interactions })+\sum_{6}^{11} \beta_{i} \cdot \\
(6 \text { Double Interactions })+\sum_{12}^{15} \beta_{i} \cdot(4 \text { Linear Terms })+\varepsilon_{i h v}
\end{gathered}
$$

where the parameter $\beta_{1}$ is the quadruple-difference estimate of interest, and indicates the extent to 
which the triple difference estimate from (2) is coming from villages that are further away from a secondary school. The estimation sample, controls, and clustering are identical to that in (2) .

\subsubsection{Non-Parametric Triple Difference Estimate (DDD by Distance to Secondary School)}

A richer picture of differential program impact can be seen by creating a non-parametric plot of the triple difference estimate in (2) as a function of the distance to the nearest secondary school. The benefits of school attendance are unlikely to depend on the distance while the costs can be thought of as linear in travel time (see sketch in Figure 3). ${ }^{9}$ The provision of a cycle therefore reduces the cost of school attendance proportional to the original distance from the nearest secondary school. Figure 3 illustrates that if the main mechanism of program impact is that it reduced the distance cost of attending school, we would expect the impact to be low in villages where there is a secondary school nearby (since the marginal impact of the cycle would be low) or where the secondary school is very far away (since the absolute cost of attending school would still be too high), and highest at intermediate distances.

\subsubsection{Estimate of Program Impact on Learning Outcomes}

Our main estimates on learning outcomes are based on the official tenth-grade board exam results for both Bihar and Jharkhand. We do not measure the impact of the program on the percentage of students who pass these exams since these could be biased downwards if academically weaker students are now more likely to go to secondary school and attempt the exam. We therefore focus our analysis on the logarithm of the absolute number of students who attempt and pass the tenth-grade exams. ${ }^{10}$ Our estimating equations take the same form as in (1) and (2) for the double and triple difference estimates respectively.

\section{Results}

\subsection{Enrollment Impact}

\footnotetext{
${ }^{9}$ Of course, the opportunity cost of the time spent in school does not vary by distance, but time spent traveling incurs not only the opportunity cost of time, but also a considerable safety cost (especially for girls). We therefore abstract from the other costs of school attendance and focus only the component that is likely to be affected by the provision of the cycle. Note that we also use the term 'distance cost' instead of 'time cost' in this paper to account for the additional costs imposed by distance beyond time to travel to the school.

${ }^{10}$ Since the population base in Bihar and Jharkhand is different, we use logs and not levels. The coefficients on the double and triple difference estimates can then be interpreted as percentage changes over the base.
} 
Table 2 presents the difference-in-difference (DD) estimate of the impact of the Cycle program based on equation (1), and columns 1-4 present these estimates with an increasingly rich set of controls. The main estimate of interest is in the first row and suggests that girls in treated cohorts were 9 to 12 percentage points more likely to be enrolled in or have completed grade 9 relative to boys in the same cohorts. One point to highlight is that the coefficient on the 'treatment' dummy (which is an indicator for being 14 or 15 years old - and hence in a 'treated' cohort) is negative, which reflects the fact that there is considerable grade repetition and that students may often enroll in or complete grade 9 later than the age at which they would be expected to if they were not repeating grades. ${ }^{11}$ The treatment effects presented should therefore be interpreted as the increase in the likelihood of girls being enrolled in or completing grade 9 at a grade-appropriate age.

An alternate way of interpreting the double difference estimate is to think of the first difference not in terms of the difference in grade 9 enrollment (or completion) between girls in older and younger cohorts, but rather in terms of the gender gap in grade 9 enrollment (or completion) in the older cohort. The double difference can then be interpreted as the difference in the gender gap in grade 9 enrollment (or completion) between the older and younger cohorts. The negative coefficient on the 'treatment' dummy is then simply interpreted as indicating that the younger cohort is less likely to have reached (or completed) grade 9, while the double difference estimate is exactly the same as in Table 2 . We defer the interpretation of the magnitude of these effects till Table 4. The coefficients on the controls are all in the expected direction, and are only shown in Table 2 for completeness and are not shown in later tables (both for space reasons and also because these are not the estimates of interest in this paper).

As discussed earlier, the validity of this DD estimate depends on not rejecting the null hypothesis of a 'parallel trend' assumption with regard to the secondary school enrollment probability of boys and girls in the absence of the program. We test this assumption using administrative data on enrollment by gender at the school level for the period $2002-2006$ (starting from the year after the splitting of Bihar into the states of Bihar and Jharkhand and till the year prior to the Cycle Program), and using the same specification as in (1) except that we

\footnotetext{
${ }^{11}$ It is also not uncommon for children to drop out of school for some time and then re-enroll, which is another explanation for being in a lower grade than would be expected if they were in an age-appropriate grade.
} 
replace the 'treatment' dummy with a continuous indicator of the year (with 2002-03 coded as 1 and 2005-06 coded as 4). These results are presented in Table 3 - Panel A (where each observation is the log of school-level enrollment by gender), and we see that the parallel trends hypothesis is rejected, with the data indicating that girls' secondary school enrollment was growing faster than that of boys (at around 5\% annually) regardless of the Cycle program.

Following the rejection of the parallel trend hypothesis within Bihar, we turn to testing the equivalent for our triple-difference specification - comparing the differential pre-program growth rates in female secondary school enrollment (relative to boys) across the neighboring states of Bihar and Jharkhand. We repeat the same analysis as above including the data from Jharkhand, and use the specification in (2), and see now that we do not reject the null of parallel trends at the school level, with the coefficient on the triple interaction term being close to zero (Table 3 - Panel B). ${ }^{12}$ It is also worth highlighting that this is a very precisely estimated zero (the standard error is 0.01 ) and we can therefore rule out differential trends of greater than $2 \%$ a year with 95\% confidence. The triple-difference estimates are therefore likely to provide an unbiased estimate of the impact of exposure to the Cycle program on girls' secondary school enrollment.

Our main triple-difference estimates of the impact of the Cycle program, based on equation (2) are presented in Table 4. The estimates with no controls and with only demographic controls (columns 1 and 2) suggest a program impact of around 10 percentage points, while including controls for household education and assets reduces the estimate to 5.2 percentage points, with no further change from including village-level controls (columns 3 and 4). The differences between the estimates in columns 2 and 3 suggest that the rate of girls' secondary enrollment catching up with those of boys may have been higher for households of greater socio-economic

\footnotetext{
${ }^{12}$ Our initial approach was to compare only the border districts across Bihar and Jharkhand and since collecting the enrollment data in Jharkhand required our field teams to visit the headquarters of each district, we only have the school-level enrollment data in Jharkhand for the 10 districts that border Bihar. As we discuss later, the restricted sample of only the border districts is too small to be adequately powered. Therefore the analysis of the parallel trends (using school-level data that had to be individually collected for each district) is based on only using the 'border' districts in Jharkhand (we have data for all districts in Bihar because the Government of Bihar facilitated this data collection), while the main analysis (using the DLHS survey) uses all the districts in Bihar and Jharkhand.
} 
status, and our preferred estimates are therefore those from Table 4 - Column 4, which has a full set of household and demographic controls (these are the same variables as shown in Table 2). ${ }^{13}$

Thus, we estimate that the Cycle program increased age-appropriate secondary school enrollment of girls in Bihar by 5.2 percentage points. To calculate the relative magnitude of this effect, we add the constant, the coefficients on the single and double interaction terms, and the coefficients on the included controls (not shown in the table) multiplied by the mean values of the controls in Bihar (shown in Table 1) and see that the base rate of age-appropriate (at 14 or 15) secondary school enrollment of girls in Bihar was 17.2 percent. The 5.2 percentage point increase therefore represents a 30\% increase in age-appropriate secondary school enrollment for girls in Bihar. Similarly, the corresponding age-appropriate secondary school enrollment rate for boys was 30 percent and our estimates show that the program bridged the gender gap in ageappropriate secondary school enrollment (of 13 percentage points) by $40 \%$.

The main threat to interpreting this estimate as the impact of the Cycle program is the possibility that there may have been other changes in Bihar during the same period (2006 2008) that also increased the likelihood of girls enrolling in secondary school. While using boys and Jharkhand as comparison groups mitigates most of these concerns, we cannot fully rule out this possibility. In particular, it is possible that the returns to education for girls in Bihar may have been increasing faster during this period or that improvement in law and order and safety in Bihar during the same period made it differentially more likely that girls would stay enrolled in secondary school. We address this concern in the next section by presenting evidence on the mechanism of program impact.

\subsection{Mechanism of Enrollment Impact}

Table 5 presents the quadruple difference estimates based on equation (3) where we decompose the DDD estimates in Table 4 by whether the respondent lived in a village that was above the median distance to a secondary school (3km). The results suggest that the DDD estimates presented in Table 4 are almost completely attributable to respondents who lived far from a secondary school. For households who are three or more kilometers away from a

\footnotetext{
${ }^{13}$ We also prefer the estimates in column 4 with a full set of household and village controls, because we document differences in observable characteristics in the sample between Bihar and Jharkhand (Table 1).
} 
secondary school, we estimate that being in a cohort that was exposed to the Cycle program led to an increase in girls' secondary school enrollment rates by nine percentage points. However, for households who were less than three kilometers away from a secondary school, we estimate that there was no impact at all (Table 5, row 3, column 4). ${ }^{14}$ The non-impact at short distances is an important result because it suggests that our reduced form estimates are not confounded by omitted variables such as differential trends in returns to education for girls in Bihar in this period (this would have led to a positive triple difference estimate at all distances).

We explore this result further by plotting the DD and DDD estimates (from tables 2 and 4) non-parametrically as a function of distance to a secondary school (as outlined in section 3.2.4). Figure 4 shows these plots, where Panel A and Panel B are the non-parametric plots of the DD estimates for Bihar and Jharkhand respectively, and Panel C shows the DDD plot as a function of distance to the nearest secondary school. The plots include bootstrapped 95\% confidence intervals. $^{15}$ The main figure of interest is Panel C, where we see the inverted-U pattern that is consistent with the prediction in section 3.2.4. The bootstrapped confidence intervals suggest that the DDD estimates are positive and significant at distances between 5 and 13 kilometers, which are in the intermediate range of distance to school at which we would expect to see a positive effect as per the sketch in Figure 3.

Panels A and B are also very interesting and highlight the importance of using Jharkhand as a control group. The consistently positive DD estimates in Jharkhand at all distances suggest that girls' age-appropriate secondary school enrollment may have been catching up anyway. However, in Jharkhand, this catch up seems more likely to have happened when secondary schools were more easily accessible, and are typically insignificant at most distances above $5 \mathrm{~km}$.

\footnotetext{
${ }^{14}$ Field interviews with head teachers suggest that it is quite common for students to walk 2 to 3 kilometers to get to secondary school, which is consistent with finding a limited impact of the bicycle in this distance range.

${ }^{15}$ The DLHS sample consists of 50 villages per district and 20 households per village. We first calculate the village-level double difference estimate (based on equation 1) for each village in the sample. These estimates are then plotted for each state as a function of distance to the nearest secondary school and the plots in Panel A and B are based on a lowess smoothing across the village-level double difference estimates at each distance. The triple difference plots the difference between the smoothed double difference plots of Bihar and Jharkhand respectively. To construct the bootstrapped confidence intervals we calculate the DD and DDD estimates from 5,000 resamples of the original data that account for the sampling procedure in the original dataset. Specifically, we account for both stratification and clustering, by ensuring that each resample contains the same number of villages in each district and we resample 50 villages with replacement in each district (to preserve the stratification), but include the full household sample from the sampled villages (to account for clustering). The confidence intervals are based on the $2.5^{\text {th }}$ and $97.5^{\text {th }}$ percentile of the distribution of estimated DD and DDD effects from this resampling procedure.
} 
Bihar also saw a considerable catch up at almost all distances, ${ }^{16}$ and so it is the triple difference that highlights the fact that most of the gains in enrollment relative to Jharkhand occur at intermediate distances.

To further probe the mechanism of impact, we examine the stated reasons for dropping out among households with girls aged 16-17 who have dropped out from school after completing eighth grade. The majority of households report the reason for dropping out as being either that 'no further education was required' or that the girl was required for work (in the house, farm, or outside). However, in 6 percent of the cases, the stated reason for dropout was that 'the school was too far away'; and in another 1.6 percent, it was that that 'transport was not available'. Thus, 7.6 percent of the cases of female drop-outs in the older cohorts were attributed to lack of school access. Our estimated treatment effect of 5.2 percentage points on the younger cohorts who were exposed to the Cycle program are therefore credibly in the range of the expected impact of an intervention that improved school access by reducing the distance cost of school. ${ }^{17}$

\subsection{Heterogeneity of Enrollment Impact}

We analyze heterogeneity of the DDD estimates presented in Table 4 as a function of several demographic and socio-economic characteristics including household assets, caste, and religion using a specification similar to the DDDD specification used in equation (3), with the corresponding characteristic replacing the "long-distance" dummy in (3). We report these results in Table 6 and the main result is that there is no significant heterogeneity along any of these characteristics. The odd columns present results using the full sample, and the even columns present results only for the villages that are 3 kilometers or further from a secondary school (where the main effects are significant), and we find the same results (of no significant heterogeneity) in both samples. Columns 1-4 include no controls (since they are based on composite indices of individual covariates), while columns 5-12 include the household and village controls shown in columns 3 and 4 of Table 2 (since these are testing heterogeneity of

\footnotetext{
${ }^{16}$ As we see in Figure 2, there are hardly any villages in Bihar that are over 20km away from a school, and the double difference estimates in Figure 4 (Panel A) are positive and significant for distances up to 20km.

${ }^{17}$ We also tried to test the impact of program ownership on bicycle ownership. Unfortunately, the DLHS only asks if a household owns a bicycle and does not ask for the number of bicycles in the household, and estimating equation (2) in the DLHS data with bicycle ownership as the dependent variable will be under-powered as a result. We estimate these regardless and as expected, find positive but insignificant effects on the likelihood of household bicycle ownership of being in Bihar and having a girl in a treated cohort.
} 
impacts across a single demographic variable at a time). The results are unchanged if villagelevel controls are added to Columns 1-4 or if the controls are dropped from columns 5-12.

\subsection{Impact on Learning Outcomes}

Our main results on educational attainment are based on official administrative data on appearance and performance in the secondary school certificate (SSC) exams. Unlike schoollevel data, there is no risk of these figures being inflated since they are obtained from the statelevel examination authorities and are based on actual records of the number of students who appeared for the tests and their performance. Since there is a two-year lag between entering secondary school and taking the exam, and the program starts in late 2006, we code 2009 and 2010 as "post" program years and 2004 to 2007 as "pre" program years. The parallel trends assumption is again rejected for the double difference and not rejected for the triple difference (as in Table 3; this table is available on request), and we therefore focus our attention on the triple-difference estimates.

Table 7 (columns 1 and 2) present results on two key outcome variables - the number of girls who appear in the SSC exam, and the number of girls who pass this exam (both in logarithms of school-level figures). We see that cohorts exposed to the Cycle program had a significant increase in the number of girls who appeared for the SSC exam (a 9.5\% increase), but that there was no increase in the number of girls who passed the exam. These results are consistent with those from other evaluations of conditional transfer programs in developing countries that find significant impacts on enrollment but typically find no impacts on learning outcomes. ${ }^{18}$

One limitation of this analysis is that our dependent variable is at the school-level and using school-level data in a triple-difference specification ignores the possibility of new schools being constructed and the redistribution of enrollment in existing schools to other schools. This may bias our estimates if such school construction is taking place at a different rate across the two states. We therefore also report the same regressions using figures aggregated at the district level

\footnotetext{
${ }^{18}$ We also try to study the impact of exposure to the program on learning outcomes using the 2007-08 ASER data collected by Pratham (a leading non-profit organization in India). This is a household survey that includes short tests of learning levels, and we find no impact on performance on these test questions using an identical triple difference specification as in (2). However, the set of test questions administered here are not really appropriate for older children since they focus on very basic literacy and numeracy (at first and second grade level), and so we do not focus on these results (which are available on request).
} 
(since students very rarely leave their district for schooling) in columns 3 and 4 . The standard errors here are much larger (since the number of observations is a lot lower when aggregated to the district level), but the point estimates are quite similar to those in columns 1 and 2, suggesting that the Cycle program did lead to an increase in the number of girls attempting the SSC exam, but that there was no increase in the number who passed the test.

It is beyond the scope of this paper to examine the reasons for non-impact of the Cycle program on learning outcomes, but possible explanations include: (a) the girls induced to stay in school as a result of the program are likely to have been drawn from the lower end of the eighth grade test score distribution, and are therefore less likely to have been able to pass the externallygraded SSC exam, (b) investments in school quality may not have kept pace with the increase in demand, which may have led to a reduction in school quality (also affecting students already enrolled), and (c) the program provided an incentive for enrollment but not for achievement. ${ }^{19}$

\section{Robustness}

\subsection{Omitted variables that differentially affect girls in Bihar as a function of distance to school}

While the results presented so far (especially Table 5 and Figure 4) strongly suggest that our reduced form estimates can be interpreted as being the causal effect of the Cycle program, there is one further concern. Specifically, it is possible that improvements in roads and law and order in Bihar would also have a greater impact on girls' school participation than boys, and that this impact may be greater as a function of distance to a secondary school in exactly the same way as sketched in Figure 3. Thus, if these improvements also differentially reduce the cost of girls' secondary school participation proportional to the distance to school in the same way that the bicycle may have, then our estimates could be confounding the impact of these other improvements with that of the Cycle program.

We address this concern by conducting a placebo test where we implement the same tripledifference specification in (2) to estimate the impact of exposure to the Cycle program on the probability of girls' age appropriate enrollment in (or completion of) the eighth grade. Since this

\footnotetext{
${ }^{19}$ It is worth noting that in 2011, the Government of Bihar attempted to address this issue by announcing an additional cash award to girls who pass with a first division score (over 60\% marks) in the SSC exam. Kremer, Miguel, and Thornton 2009 show that a similar program in Kenya led to increased test scores.
} 
is the grade just below the ninth grade, improvements in roads, law and order, and safety should affect girls in this cohort in comparable ways. However, girls in eighth grade were not eligible for the Cycle program, which makes them an ideal group for a placebo test. We present these results in Table 8 and see that there was no impact at all of being in a cohort exposed to the Cycle program on eighth-grade enrollment. ${ }^{20}$

We are therefore confident that the main reduced form estimates presented in Table 4 can be interpreted as the causal impact of being exposed to the Cycle program. Nevertheless, it is possible that the investments in roads, and law and order - while not causing the increase in ninth grade girls' enrollment on their own - were complements to the Cycle program. So, it is important to caveat our results by noting that the provision of bicycles on their own may not have had the same impact in the absence of these complementary investments. ${ }^{21}$

\subsection{Border Districts and Clustering}

We consider a further robustness check by restricting the sample for our main tripledifference estimates to just the border districts in Bihar and Jharkhand. We present these results in Table 9 and see that the point estimates are practically indistinguishable from those in the full sample used in Table 4. However, restricting the analysis to the border districts reduces the sample size to a third of that in Table 4, and the significance of the coefficient on the tripleinteraction term is therefore lower in each of the four specifications. Our main analysis is therefore based on the full sample (since the sample using just the border districts is underpowered), ${ }^{22}$ but the unchanged coefficients from using just the 'border district' sample

\footnotetext{
${ }^{20}$ The specification is identical to that used for Table 4, except that the 'treated' cohorts are now aged 13-14 (instead of 14-15) and the 'control' cohorts are now aged 15-16 (instead of 16-17), because we are looking at age appropriate enrollment in eighth grade as opposed to ninth grade. The 2-year gap between the 'treated' and 'control' cohorts corresponds exactly to the introduction of the Cycle program (as in Table 4).

${ }^{21}$ However, it is also worth noting that even though the new government in Bihar (that took office in December 2005) took steps to improve road construction and law and order starting in 2006, it took time to see results. Chakrabarti (2013) documents these initiatives and notes that after many years of neglect, several changes had to be made to procurement procedures and contractor selection before accelerated road construction could take place. The lag between policy change and implementation suggests that our estimates, which are based on the first two years of the new government (2006-07) may not be highly sensitive to the complementary investments in roads. This may also explain the non-effect when we look at changes in girls enrollment in grade 8 in the same time period (Table 8). ${ }^{22}$ It is worth noting that a triple-difference identification strategy of the sort used in this paper requires very large samples to have adequate power, and we are fortunate that the DLHS-3 has a large enough sample size at the state level for us to have adequate power (the DLHS-3 is among the largest household surveys ever done in India - and is five times larger than the full rounds of the NSS, which is the main household survey of income and consumption in India). As a comparison, Duflo (2001) required access to a restricted Indonesian intercensal survey dataset (that
} 
increase our confidence in the robustness of the results. Finally, our default analysis clusters the standard errors at the village-level (one level above the unit of observation), but we also cluster the standard errors at the district level and the coefficients on the triple interaction terms in Table 4 continue to be significant in all four specifications, though at lower levels of significance (tables available on request).

\subsection{Replication in a Different Dataset}

As a further test of robustness, we use the ASER 2007-08 data (Pratham 2008) to estimate the impact of being in a cohort exposed to the Cycle program on female secondary school enrollment using the same triple-difference specification with controls as in (2). We find almost identical point estimates in this dataset as well (a 6 percentage point increase in girls' enrolment), but they are not significant. This is because ASER is a smaller survey and only collects education data for household members up to age16, and the size of the estimation sample is therefore less than a third of that in the DLHS-3 data used in Table 4, which create the same limitations discussed in footnote 22 (tables available on request).

\subsection{Spillovers}

A further concern may be the possibility of intra-household spillovers from the Cycle program. In particular, there may be a concern that if boys in the house undertake more chores because their sisters go to school (and reduce their own schooling as a result), then our results may be biased upwards. We believe that this is quite unlikely in the patriarchal culture of rural Bihar and if anything the direction of spillovers is likely to be the other way - with more boys who may have dropped out now being induced to continue to school as a result of seeing girls in the village continue to secondary school. While we cannot test this directly (given that our core identification strategy relies on differences relative to boys), other experimental studies on transfers targeted to girls in developing countries have typically found a positive spillover to boys in the household (see Kim, Alderman, and Orazem 1999, and Kazianga, de Walque, and Alderman 2012 for evidence from programs in Pakistan and Burkina Faso respectively). Thus,

covered over 150,000 individuals) to have adequate power for a similar triple-difference identification strategy. Replicating the same specification as Duflo (2001) in the third wave of the Indonesian Family Life Survey (IFLS-3) yields positive point estimates on the impact of school construction on education attainment, but these are insignificant because of the considerably smaller sample size (though the IFLS is a large household survey). 
to the extent that there are spillovers from girls to boys, we believe that they will lead to our estimated effect sizes being a lower bound on the true effect. ${ }^{23}$

\section{Cost Effectiveness and Discussion}

\subsection{Cost Effectiveness}

The most natural benchmark for the cost effectiveness of the Cycle program would be conditional cash transfer (CCT) programs that are offered to households conditional on girls remaining enrolled in secondary school. Unfortunately, there are no credible evaluations of CCT programs in India and no experimental evaluations in South Asia more broadly (unlike in Africa and Latin America). The closest set of relevant estimates are from a conditional girls' stipend program in Pakistan that aimed at increasing girls' enrollment in grades 6-8 between 2003 and 2005. Chaudhury and Parajuli (2010) use a similar triple-difference approach and estimate that the program (which cost \$3/month per recipient) increased female enrollment in grades 6-8 by 9 percent (a four percentage point increase on a base enrollment of 43\%).

In contrast, the Cycle program cost less than $\$ 1 /$ month per recipient ${ }^{24}$ and being exposed to it led to a 30 percent increase in female secondary school enrollment. Thus, the Cycle program had both a higher absolute impact (5 versus 4 percentage points) and a much higher impact relative to base enrollment rates (30 percent relative to 9 percent) than a comparable CCT program, though it spent considerably less per recipient and targeted secondary as opposed to middle school (with female dropout being a much bigger challenge at the secondary level). Thus, the Cycle program appears to have been much more cost effective at increasing female school participation than comparable CCT programs (which are the most commonly used policy instrument for improving female school participation in developing countries), and was likely to have been even more cost effective for girls who lived further away from a secondary school.

\footnotetext{
${ }^{23}$ One further test we do is to plot the single difference for boys and girls for Bihar by distance (analogous to Figure 4, but with the first differences for boys and girls in Bihar) and we see no noticeable pattern in the first difference for boys as a function of distance, whereas there is a clear inverted-U for the girls. The figures clearly suggest that spillovers to boys in the household were not a first-order concern and are available on request.

${ }^{24}$ The value of the transfer made available for buying the cycle was around $\$ 45$. We assume that the cycle lasts for 4 years, which is a conservative estimate relative to anecdotal evidence that bicycles are an important asset in rural Bihar that are maintained and used for many years. More formally, the Indian tax code allows vehicles to be depreciated linearly at 15\% per year, implying a life of 6 to 7 years. Our estimate of a 4-year life for the bicycle is therefore conservative even by this standard.
} 
Finally, the low base rate of female secondary school enrollment means that the number of girls who received the transfer who would have enrolled anyway was quite low. ${ }^{25}$

\subsection{Cash vs. Kind Transfers}

The evidence above that the conditional kind transfer of a bicycle may have been more cost effective at increasing girls' secondary school enrollment relative to an equivalent conditional cash transfer raises some interesting issues for the broader debate on cash versus kind transfers as tools for social policy in developing countries. In particular, given evidence in other Indian settings that in-kind provision of school inputs were substituted away by households (see Das et al. 2013), it is worth thinking about the circumstances under which an in-kind transfer may do better in promoting education outcomes relative to an equivalent cash transfer and the extent to which those conditions were met in this case.

First, a cycle for an adolescent girl was unlikely to have been infra-marginal to pre-program household spending, and therefore would have been difficult to substitute away. On a related note, field interviews suggest that the public ceremonies in schools accompanying the payments to families to buy a bicycle would have made it socially difficult for families to sell the bicycle ex post, thereby making it less likely that the in-kind transfer would be monetized.

Second, the bicycle directly reduced the marginal cost of schooling incurred by the girl on a daily basis, and may therefore have had a greater impact relative to a transfer that simply augmented the household budget. Of course, if a bicycle would alleviate a binding constraint to school attendance, it should still be possible for a household to use a cash transfer to buy a bicycle on their own. So why might this not happen as easily? One reason is that even households that may have wanted to buy a cycle with the equivalent cash transfers may face credit constraints that make it difficult for households to transform small monthly cash transfers into an expensive capital good that needs to be bought up front. A second (and perhaps more important) reason is that in-kind provision may change the default of what the money would be spent on, and remove it from the sphere of intra-household bargaining. Thus, from the perspective of a social planner who seeks to influence the intra-household allocation of a

\footnotetext{
${ }^{25}$ Of course, the welfare cost of the transfer to infra-marginal households is not the value of the transfer but only the deadweight loss incurred by raising the revenue for the transfer (and the cost of administering the transfer), but a low extent of infra-marginal transfers will still improve the cost-effectiveness of the program.
} 
transfer, the provision of the transfer in the form of a bicycle may help the transfer 'stick' to the intended recipient (the girl) as opposed to augmenting the overall household budget and be subject to intra-household bargaining and allocation (where the girl would likely only receive her Pareto share of the transfer). ${ }^{26}$

Third and finally, it is likely that the program as implemented generated positive spillovers relative to what an equivalent conditional cash transfer would have done. The Cycle program can be considered as providing a 'signal' that helped households coordinate the spending of the transfer on a bicycle, which in turn is likely to have generated positive externalities including (a) greater safety when girls cycle to school together, and (b) a change in social norms with respect to the social acceptability of girls' being able to leave the village to attend school. The latter channel may be particularly important in a patriarchal context such as that of rural Bihar, and it is important to note that our estimates of program impact could be driven not just by the reduction of the 'distance cost' of schooling to individual girls, but also by changes in safety and social norms induced by the mass provision of bicycles to girls attending secondary school.

\subsection{Historical Perspective on Women's Empowerment}

Scholars of the history of women's suffrage and empowerment in the United States have noted the important role played by the bicycle in this process, with the opening quote from Susan Anthony highlighting the transformative role played by bicycles in enhancing the mobility, freedom, and independence of women in the $19^{\text {th }}$ century (in addition to playing a role in changing social norms on women's clothing). ${ }^{27}$ It is useful to keep this historical perspective in mind to understand the potentially transformative long-term potential of the Cycle program to not just improve female secondary school attendance, but to also empower girls' beyond school attendance by increasing their mobility and independence in a deeply patriarchal society.

The discussion of the role of the bicycle in women's empowerment suggests an additional reason for why an in-kind transfer like the bicycle may in this context be more effective at

\footnotetext{
${ }^{26}$ Of course, other members in the household can use the bicycle during non-school hours thus generating a pay-off to the entire household - but it is likely that the first claim on the bicycle would be that of the girl who owns it. ${ }^{27}$ See Macy (2011) for a detailed history of the role of the bicycle in women's empowerment in the United States. The full quote from Susan Anthony is: "Let me tell you what I think of bicycling. I think it has done more to emancipate women than anything else in the world. I rejoice every time I see a woman ride by on a wheel. It gives her a feeling of self-reliance and independence the moment she takes her seat; and away she goes - the picture of untrammeled womanhood." (Harper 1898)
} 
improving female education outcomes than an equivalent conditional cash transfer to the household. As Basu (2006) notes, not only do household Pareto weights determine current consumption shares, but current decisions within the household may also affect future balance of power and change future Pareto weights. Thus, holding the Pareto weight of a girl in the household budget constant, households (and extended families and communities) in strongly patriarchal settings like rural Bihar may be more inclined to direct the girl's share towards consumption (or saving for marriage) rather than to make investments for girls (such as a bicycle) that can dynamically improve their bargaining power over time in their communities. In such a context, the provision of a bicycle may not only help ensure that the entire transfer 'sticks' to the girl who was targeted, but can help empower adolescent girls by 'bypassing' entrenched patriarchal household decision-making processes, because it is possible that households would not choose to buy a bicycle on their own even if they were somehow constrained to spend the entire value of the cash transfer on the 'targeted' girl.

While empowerment is difficult to quantify, several qualitative accounts of the Cycle program in Bihar have highlighted that the program has played a highly visible and transformative role in increasing the mobility and confidence of young girls. ${ }^{28}$ The Chief Minister of Bihar echoed the same sentiments expressed by Susan Anthony by noting that: "Nothing gives me a greater sense of fulfillment of a work well done than seeing a procession of school-bound, bicycle-riding girls. It is a statement for social forward movement, of social equality and of social empowerment (Swaroop 2010)."29 Our quantitative estimates showing that exposure to the Cycle program bridged the gender gap in secondary school enrolment by 40 percent, and that the program was much more cost effective than an equivalent cash transfer lend support to the widespread perception that the Cycle program has played a transformative role in empowering girls and bridging gender gaps in secondary school participation in rural Bihar.

\section{Conclusion}

The Cycle program in the state of Bihar has been one of the most visible policy initiatives for improving female educational attainment in India in the past decade, and has been widely

\footnotetext{
${ }^{28}$ Sources include Debroy (2010), Kumar (2010), Swaroop (2010), Nayar (2012) and Chakrabarti (2013)

${ }^{29}$ Similarly, Chakrabarti (2013) notes that: "Today, one of the commonest sights on most roads in Bihar is a group of girls in school uniforms bicycling together, to or from school. The social impact of this on the status of women and the demand for education itself has stretched far beyond what any cold statistic can ever capture (page 128)."
} 
imitated in other states. However, while the program has been politically popular and received wide media coverage, it has been challenging to credibly measure its impact on girls' secondary school enrollment because the program was rolled out across the entire state at the same time.

In this paper, we use a large representative household dataset collected 18 months after the inception of the Cycle program and use a triple and quadruple difference approach to credibly estimate the impact of the Cycle program on girls' secondary school enrollment and on their appearance and performance on the secondary school certificate (SSC) exam. We find that the rate of age-appropriate participation in secondary school for girls increases by 30 percent in cohorts exposed to the Cycle program (a 5.2 percentage point increase on a base of $17.2 \%$ ) and also find strong evidence to suggest that the mechanism of impact was the reduction in the 'distance cost' of attending school induced by the bicycle. We find a significant increase in the number of girls who appear for the SSC exam, suggesting that the increase in enrollment was not just on paper, but led to a real increase in school participation. However, we find no impact of the program on the number of girls who pass the SSC exam.

Comparisons with conditional cash transfer programs in other South Asian contexts suggest that the Cycle program was much more cost effective at increasing girls' secondary school enrollment than an equivalent-valued cash transfer. Given the importance of increasing women's education attainment in developing countries like India (especially in its most under-developed regions) and the fiscally-constrained policy environment, these results are important and suggest that the Cycle program was not just politically popular but also much more cost-effective than the most frequently considered and implemented policy alternative to increase girls' secondary school enrollment in developing countries in the past couple of decades (CCT's).

From a policy perspective, it is also worth reflecting on why the Cycle program was implemented effectively, with leakage rates as low as 3\% (Ghatak et al. 2013) even in a context of high leakage and corruption in other public programs. Discussions with policy makers, field officials, and researchers suggest that the reasons for low leakage in the Cycle program included: (a) universal eligibility - every girl enrolled in 9th grade was entitled to the grant for the bicycle, which removed officials' discretion in determining beneficiaries; (b) the transparent and one-time nature of the transfer, which made it easier to monitor than several ongoing smaller transfers; (c) the public ceremonies for awarding the cash to purchase bicycles in schools, which provided an 
easy platform for beneficiaries to notice irregularities and to report grievances; (d) the demographic group that was eligible for the benefit (households enrolling girls in secondary school) is likely to have been considerably more empowered to begin with (as seen by the coefficients on the household controls in Table 2) relative to the poorer and more disadvantaged recipients of other public programs, making it more difficult for officials to deny them benefits; and (e) commitment of the political leadership of the state towards the program, and the clear political rewards from a program that was highly visible to beneficiaries and communities and relatively easy to implement (Mani and Mukand 2007). These design features are all easy to translate to other low-income settings, suggesting that it may be worth scaling up similar programs in other developing countries as a promising policy option to increase low rates of female secondary school participation.

The historical experience in countries like the United States points to the bicycle having played an important role in women's emancipation, and it is widely believed that the Cycle program may have had similar effects in Bihar. While we have focused on education outcomes in this paper, it is likely that the increase in secondary education (and women's empowerment more broadly) induced by the program may have longer term effects on outcomes such as age of marriage and total fertility (as shown experimentally by Jensen 2012). Given that Bihar had the highest population growth rate among major Indian states in the last decade (growing over 25\% between the 2001 and 2011 censuses), future research should study these additional outcomes to understand whether the Cycle program may have helped to accelerate a demographic transition in Bihar towards lower fertility and greater human capital investment in children.

Finally, the main area of concern for policy makers from our results is the finding that the Cycle program had no impact on the number of girls who passed the SSC exam in spite of the significant increases in female enrollment and the number of girls attempting the SSC exam. The challenge of converting increases in inputs (including student enrollment) into learning outcomes is a fundamental one that is faced at all levels of the Indian education system. However, while there is a growing body of evidence on effective interventions in primary education in developing countries such as India (see Muralidharan 2013 for a review) there is relatively little corresponding evidence on cost-effective interventions to improve the quality of secondary education in low-income settings. This is an important area for future research. 


\section{References:}

Aslam, Monazza, Anuradha De, Geeta Kingdon, and Rajeev Kumar. 2011. "Economic Returns to Schooling and Skills - An Analysis of India and Pakistan." In Education Outcomes and Poverty in the South, edited by Christopher Colclough. London: Routledge.

Baird, Sarah, Craig Mcintosh, and Berk Ozler. 2011. "Cash or Condition: Evidence from a Cash Transfer Experiment." Quarterly Journal of Economics no. 126:1709-1753.

Basu, Kaushik. 2006. "Gender and Say: A Model of Household Behavior with Endogenously Determined Balance of Power." Economic Journal no. 116 (511):558-580.

Bleakley, Hoyt. 2007. "Disease and Development: Evidence from the Eradication of Hookworm in the American South." Quarterly Journal of Economics no. 122 (1):73-117.

Burde, Dana, and Leigh Linden. 2013. "Bringing Education to Afghan Girls: A Randomized Controlled Trial of Village-Based Schools." American Economic Journal: Applied Economics no. 5 (3):27-40.

Chakrabarti, Rajesh. 2013. Bihar Breakthrough: The Turnaround of a Beleaguered State. New Delhi: Rupa Publications.

Chaudhury, Nazmul, and Dilip Parajuli. 2010. "Conditional cash transfers and female schooling: the impact of the female school stipend programme on public school enrolments in Punjab, Pakistan." Applied Economics no. 42 (3565-3583).

Chetty, Raj, John N Friedman, and Emmanuel Saez. 2013. "Using Differences in Knowledge Across Neighborhoods to Uncover the Impacts of the EITC on Earnings." American Economic Review (forthcoming).

Das, Jishnu, Stefan Dercon, James Habyarimana, Pramila Krishnan, Karthik Muralidharan, and Venkatesh Sundararaman. 2013. "School Inputs, Household Substitution, and Test Scores." American Economic Journal: Applied Economics no. 5 (2):29-57.

de Janvry, Alain, Frederico Finan, Elisabeth Sadoulet, and Renos Vakis. 2006. "Can Conditional Cash Transfer Programs Serve as Safety Nets in Keeping Children at School and from Working When Exposed to Shocks?" Journal of Development Economics no. 79 (2):349-373.

Debroy, Bibek. 2010. "A bicycle built for many." The Indian Express.

Dhaliwal, Iqbal, Esther Duflo, Rachel Glennerster, and Caitlin Tulloch. 2012. Comparative CostEffectiveness Analysis to Inform Policy in Developing Countries: A General Framework with Applications for Education. MIT.

Duflo, Esther. 2001. "Schooling and Labor Market Consequences of School Construction in Indonesia: Evidence from an Unusual Policy Experiment." The American Economic Review no. 91 (4):795-813.

Filmer, Deon, and Norbert Schady. 2011. "Does More Cash in Conditional Case Transfer Programs Always Lead to Larger Impacts on School Attendance?" Journal of Development Economics no. 96 (1):150-157.

Fiszbein, Ariel, and Norbert Schady. 2009. Conditional Cash Transfers: Reducing Present and Future Poverty. Washington DC: World Bank.

Ghatak, Maitreesh, Chinmaya Kumar, and Sandip Mitra. 2013. Cash versus kind: Understanding the preferences of the bicycle-programme beneficiaries in Bihar. London: International Growth Center.

Harper, Ida Husted. 1898. The life and work of Susan B. Anthony: including public addresses, her own letters and many from her contemporaries during fifty years: Bowen-Merrill. 
Hornbeck, Richard. 2010. "Barbed Wire: Property Rights and Agricultural Development." Quarterly Journal of Economics no. 125 (2):767-810.

Jayachandran, Seema, and Adriana Lleras-Muney. 2009. "Life Expectancy and Human Capital Investments: Evidence from Maternal Mortality Declines." Quarterly Journal of Economics no. 124 (1):349-397.

Jensen, Robert. 2012. "Do Labor Market Opportunities Affect Young Women's Work and Family Decisions? Experimental Evidence from India." Quarterly Journal of Economics no. 127 (2):753-792.

Kazianga, Harounan, Damien de Walque, and Harold Alderman. 2012. "Educational and Child Labour Impacts of Two Food-for-Education Schemes: Evidence from a Randomised Trial in Rural Burkina Faso." Journal of African Economies:1-38.

Kazianga, Harounan, Dan Levy, Leigh Linden, and Matt Sloan. 2013. "The Effects of "GirlFriendly" Schools: Evidence from the BRIGHT School Construction Program in Burkina Faso." American Economic Journal: Applied Economics no. 5 (3):41-62.

Kim, Jooseop, Harold Alderman, and Peter Orazem. 1999. "Can Private School Subsidies Increase Enrollment for the Poor? The Quetta Urban Fellowship Program." World Bank Economic Review no. 13 (3):443-65.

Kremer, Michael, Edward Miguel, and Rebecca Thornton. 2009. "Incentives to learn." Review of Economics and Statistics no. 91 (3):437-456.

Kremer, Michael, Karthik Muralidharan, Nazmul Chaudhury, F. Halsey Rogers, and Jeffrey Hammer. 2005. "Teacher Absence in India: A Snapshot." Journal of the European Economic Association no. 3 (2-3):658-67.

Kumar, Nitish. 2010. Mukhyamantri Balika Cycle Yojna. In http://nitishspeaks.blogspot.com/2010/04/mukhyamantri-balika-cycle-yojna.html.

Linden, Leigh, and Kartini Shastry. 2012. "Grain Inflation: Identifying Agent Discretion in Response to a Conditional School Nutrition Program." Journal of Development Economics no. 99 (128-138).

Macy, Sue. 2011. Wheels of Change: How Women Rode the Bicycle to Freedom (With a Few Flat Tires Along the Way): National Geographic Society.

Mani, Anandi, and Sharun Mukand. 2007. "Democracy, Visibility, and Public Good Provision." Journal of Development Economics no. 83:506-529.

Muralidharan, Karthik. 2013. "Priorities for Primary Education Policy in India’s 12th Five-year Plan." India Policy Forum no. 9:1-46.

Nayar, Abhinav. 2012. Conditioning Cash Transfers: Bihar's Bicycle Scheme. Yale.

Nussbaum, Martha C. 2011. Creating Capabilities: Belknap Press.

Pratham. 2008. Annual Status of Education Report.

Pritchett, Lant. 2012. Impact Evaluation and Political Economy: What Does the "Conditional" in "Conditional Cash Transfers" Accomplish? In Center for Global Development Blog.

Schultz, Paul T. 2004. "School subsidies for the poor: evaluating the Mexican Progresa poverty program." Journal of Development Economics no. 74 (1):199-250.

Sen, Amartya. 1993. "Capability and Well-Being." In The Quality of Life, edited by Martha C Nussbaum and Amartya Sen, 30-53. Oxford: Clarendon Press.

Swaroop, Vijay. 2010. "Bihar's virtuous cycle." The Mint.

World Bank. 2011. World Development Report 2012: Gender Equality and Development. Washington DC: World Bank. 


\section{Table 1: Descriptive Statistics}

Bihar

0.309

(0.46)

0.543

(0.50)

0.485

(0.50)

0.19

(0.39)

0.022

(0.15)

0.588

(0.49)

0.846

(0.36)

0.151

(0.36)

4.32

(5.03)

0.855

(0.35)

0.947

(0.22)

0.289

$(0.45)$

0.272

(0.45)

0.199

(0.40)

0.068

(0.25)

0.099

(0.30)

0.323

(0.47)

7.351

(9.94)

7.792

(1.17)

18,453
Jharkhand

0.337

(0.47)

0.586

(0.49)

0.473

(0.50)

0.136

(0.34)

0.361

(0.48)

0.423

(0.49)

0.646

(0.48)

0.118

(0.32)

3.94

(4.43)

0.953

(0.21)

0.932

(0.25)

0.401

(0.49)

0.305

(0.46)

0.259

(0.44)

0.048

(0.21)

0.062

(0.24)

0.213

(0.41)

12.154

(12.81)

6.874

11,842

Observations

Notes: The data is from the Third Wave of the District-Level Health Survey (DLHS-3) in India which was conducted in the year 2007-08. The estimation sample is restricted to children aged 14 to 17 living in the states of Bihar and Jharkhand. Standard deviations of all variables are in parentheses. 
Table 2: Difference-in-Difference (DD) Estimate of the Impact of Being Exposed to the Cycle Program on Girl's Secondary School Enrollment

Treatment group $=$ Age 14 and 15 Control group $=$ Age 16 and 17

Treat×Female dummy

Treat

Female dummy

Social group: Scheduled caste

Social group: Scheduled tribes

Social group: Other backward caste

Social group: Hindu

Social group: Muslim

Household head years of schooling

Household head male dummy

Owns Less than 5 Acres of Land

Below poverty line dummy

Household owns TV/Radio

Household has electricity

Middle school in village

Bank in village

Post office in village

Distance to bus station

Log (Village current population)

Constant

Demographic controls

$\mathrm{HH}$ socio-economic controls

Village level controls

Observations

R-squared

\section{Dependent variable: Enrolled in or completed grade 9}

(1)

$0.123^{* * *}$

(0.0149)

$-0.192^{\star \star *}$

(0.0108)

$-0.186^{\star \star *}$

(0.0117)

(2)
(2)

$\mathbf{0 . 1 1 4} 4^{\star \star \star}$
$(\mathbf{0 . 0 1 4 4 )}$
$-0.184^{\star \star \star}$
$(0.0106)$
$-0.178^{\star \star \star}$
$(0.0112)$
$-0.337^{\star \star \star}$
$(0.0144)$
$-0.340^{\star \star \star}$
$(0.0308)$
$-0.223^{\star \star \star}$
$(0.0126)$
-0.115
$(0.0823)$
$-0.349^{\star \star \star}$
$(0.0831)$

$0.114^{\star \star *}$

$-0.184^{\text {*** }}$

$(0.0106)$

$0.0112)$

$-0.337^{\star \star *}$

(0.0308)

$0.0126)$

$-0.115$

-0.349 *ᄎ*

(0.0831) $0.823^{\text {*** }}$

(0.0831)

$$
\begin{gathered}
0.475^{\star \star *} \\
(0.00980)
\end{gathered}
$$

No
No
No

18,453

0.038
Yes

No

No

18,453

0.106
(3)

$0.0903^{* * *}$

(0.0135)

$-0.167^{\star \star *}$

(0.00996)

$-0.168^{\star \star *}$

(0.0104)

$-0.163^{\star \star \star}$

(0.0140)

$-0.157^{\star \star *}$

(0.0283)

$-0.108^{\star \star \star}$

(0.0115)

$-0.0385$

(0.0580)

$-0.182^{\star \star *}$

(0.0595)

0.0248 ***

(0.00201)

$-0.0741^{\text {** }}$

(0.0117)

$-0.0628^{\star \star *}$

(0.0196)

$-0.0623^{\star \star *}$

(0.00854)

$0.104^{\star \star *}$

(0.00983)

$0.102^{\text {** }}$

(0.0113)

(4)

(0.0134)

$-0.166^{\star \star *}$

(0.00997)

$-0.167^{\text {*** }}$

(0.0103)

$-0.161^{\text {** }}$

(0.0140)

$-0.153^{\star \star \star}$

(0.0284)

$-0.107^{\text {** }}$

(0.0115)

$-0.0376$

(0.0568)

$-0.179^{\star \star \star}$

(0.0583)

$0.0248^{\star \star *}$

(0.00200)

$-0.0731^{\text {** }}$

(0.0116)

$-0.0644^{\star \star *}$

(0.0196)

$-0.0624^{\star \star \star ~}$

(0.00850)

$0.104^{\star \star *}$

(0.00986)

0.0978 ***

(0.0113)

0.0174

(0.0180)

$0.0258^{*}$

(0.0149)

0.00882

(0.00992)

$-0.000858^{* *}$

(0.000411)

$-0.00390$

(0.00369)

$0.604^{\star \star \star} \quad 0.633^{\star \star \star}$

(0.0644) (0.0696)

Yes

Yes

No

18,353

0.222
Yes

Yes

Yes

18,331

0.223

Notes: ${ }^{*} p<0.1 ;{ }^{* \star} p<0.05 ;{ }^{\star \star \star} p<0.01$. Standard errors clustered by village ID are in parentheses. 


\section{Table 3: Testing the Parallel Trend Assumption}

Dependent variable: Log (9th Grade Enrollment)

PANEL A: Testing Parallel Trends for the Difference-in-Difference (DD)

\begin{tabular}{|c|c|}
\hline Female Dummy $\times$ Year & $\begin{array}{c}0.0518^{\star * *} \\
(0.00)\end{array}$ \\
\hline Female Dummy & $\begin{array}{c}-0.870^{\star \star *} \\
(0.06)\end{array}$ \\
\hline Year (time trend) & $\begin{array}{c}0.0852^{\star \star \star} \\
(0.01)\end{array}$ \\
\hline Constant & $\begin{array}{c}4.235^{\star \star *} \\
(0.05)\end{array}$ \\
\hline Observations & 20,266 \\
\hline R-squared & 0.167 \\
\hline
\end{tabular}

PANEL B: Testing Parallel Trends for the Triple Difference (DDD)

Female Dummy×Year×Bihar dummy

$-0.0100$

$(0.01)$

Female DummyxYear

$0.0618^{\star \star *}$

$(0.01)$

Female Dummy×Bihar dummy

0.175

$(0.11)$

Bihar dummyxYear

0.0290 **

Female dummy

$-1.045^{\star \star \star}$

(0.09)

Year (time trend)

$0.0562^{\star \star \star}$

(0.01)

Bihar dummy

$-0.123$

(0.12)

Constant

$4.358^{\star \star \star}$

Observations

22,279

R-squared

0.171

Notes: The analysis uses administrative data on enrollment at the school level by gender and grade in 38 districts in Bihar and 10 border districts in Jharkhand. The data covers the 4 school years after the bifurcation of the old unified state of Bihar into the states of Bihar and Jharkhand, and prior to the launch of the Cycle Program (2002-03 through 2005-06). ${ }^{\star} p<0.1 ;{ }^{* \star} p<0.05 ;{ }^{* \star *} p<0.01$. Standard errors clustered by Disrict ID are in parentheses. 


\section{Table 4: Triple Difference (DDD) Estimate for the Impact of Being Exposed to the Cycle Program on Girl's Secondary School Enrollment}

Treatment group = Age 14 and 15

Control group $=$ Age 16 and 17

Treat $\times$ Female dummy $\times$ Bihar dummy

Treat $\times$ Female dummy

Treat×Bihar dummy

Female dummy $\times$ Bihar dummy

Treat

Female dummy

Bihar dummy

Constant

Demographic controls

$\mathrm{HH}$ socio-economic controls

Village level controls

Observations

R-squared

\section{Dependent variable: Enrolled in or completed grade 9}

(1)

\section{$0.103^{* * *}$}

(0.0302)

0.0195

(0.0263)

$-0.0437^{* *}$

(0.0179)

$-0.0942^{\star \star \star}$

(0.0233)

$-0.148^{\star * *}$

(0.0143)

$-0.0915^{\star \star *}$

(0.0202)

0.0115

(0.0163)

$0.464^{\star * *}$

(0.0130)

No
No
No
30,295
0.035

(2)

$0.0912^{\star * *}$
$(0.0294)$

0.0235

(0.0256)

$-0.0418^{\star *}$

(0.0177)

$-0.0905^{\star \star \star}$

(0.0226)

$-0.143^{\star \star \star}$

(0.0142)

-0.0880 ***

(0.0196)

$-0.0437^{\star \star *}$

(0.0165)

$0.771^{\star \star \star}$

(0.0240)

Yes

No

No

30,295

0.088
(3)

(4)

$\begin{array}{cc}\mathbf{0 . 0 5 1 6} & \mathbf{0 . 0 5 1 5 ^ { \star * }} \\ \mathbf{( 0 . 0 2 5 2 )} & \mathbf{( 0 . 0 2 5 2 )} \\ 0.0385^{\star} & 0.0385^{\star} \\ (0.0214) & (0.0214) \\ -0.0287^{\star} & -0.0278^{\star} \\ (0.0160) & (0.0161) \\ -0.0671^{\star \star \star} & -0.0658^{\star \star \star} \\ (0.0199) & (0.0200) \\ -0.138^{\star \star \star} & -0.138^{\star \star \star} \\ (0.0127) & (0.0127) \\ -0.100^{\star \star \star} & -0.101^{\star \star \star} \\ (0.0170) & (0.0171)\end{array}$

-0.0324 **

(0.0145)

$-0.0451^{\star \star \star}$

(0.0146)

$0.593^{\star \star *}$

(0.0266)

$0.561^{\star \star *}$

(0.0396)

Yes
Yes
No
30,147
0.207

Yes

Yes

Yes

30,112

0.208

Notes: ${ }^{*} p<0.1 ;{ }^{*} p<0.05 ;{ }^{* *} p<0.01$. Standard errors clustered by village ID are in parentheses. The demographic, socio-economic, and village controls are the same as those shown in Table 2 
Table 5: Quadruple Difference (DDDD) Estimate for the Impact of Being Exposed to the Cycle Program on Girl's Secondary School Enrollment by Distance to Secondary School ("Long Distance" = Above Median Distance)

Dependent variable: Enrolled in or completed grade 9

Treatment group = Age 14 and 15

Control group = Age 16 and 17

Treat $\times$ Female dummy $\times$ Bihar dummy $\times$ Long distance

Treat $\times$ Female dummy $\times$ Long distance

Treat $\times$ Female dummy $\times$ Bihar dummy

Female dummy $\times$ Bihar dummy $\times$ Long distance

Treat×Bihar dummy $\times$ Long distance

Treat×Female dummy

Treat $\times$ Long distance

Treat×Bihar dummy

Female dummy $\times$ Long distance

Female dummy $\times$ Bihar dummy

Bihar dummy $\times$ Long distance

Treat

Female dummy

Bihar dummy

Long distance

Constant

Demographic controls

$\mathrm{HH}$ socio-economic controls

Village level controls

Observations

R-squared
(1)

0.0940

(0.0578)

$-0.0788$

(0.0496)

0.0426

(0.0410)

$-0.0826^{\star}$

(0.0450)

$-0.0285$

(0.0363)

0.0720 **

(0.0349)

0.0367

(0.0291)

$-0.0233$

(0.0274)

0.0654 *

(0.0384)

$-0.0419$

(0.0322)

0.0136

(0.0339)

$-0.172^{\star \star \star}$

(0.0229)

$-0.135^{\star * \star}$

(0.0276)

$-0.00856$

(0.0264)

$-0.0753^{\star * *}$

(0.0277)

$0.513^{\text {** }}$

(0.0228)

No

No

No

30,295

0.039
(2)

0.0875

(0.0560)

$-0.0803^{\star}$

(0.0480)

0.0338

(0.0394)

-0.0746 *

(0.0433)

$-0.0254$

(0.0356)

0.0770 **

(0.0334)

0.0389

(0.0287)

$-0.0225$

(0.0267)

$0.0633^{*}$

(0.0370)

$-0.0426$

(0.0307)

0.0216

(0.0315)

$-0.168^{\star * \star}$

(0.0223)

-0.130 ***

(0.0262)

$-0.0658^{\star \star *}$

(0.0243)

$-0.0733^{\star \star \star}$

(0.0257)

$0.816^{\star \star \star}$

(0.0279)

Yes

No

No

30,295

0.091
(3)

$0.0885^{*}$

(0.0502)

$-0.0737^{*}$

(0.0426)

$-0.00513$

(0.0376)

$-0.0694^{*}$

(0.0392)

$-0.00926$

(0.0329)

$0.0876^{\star \star *}$

(0.0324)

0.0316

(0.0263)

$-0.0184$

(0.0252)

0.0576 *

(0.0335)

$-0.0227$

(0.0291)

0.00695

(0.0277)

$-0.159^{\star * *}$

(0.0210)

$-0.138^{\star * *}$

(0.0251)

$-0.0434^{\star *}$

(0.0212)

$-0.0444^{* *}$

(0.0226)

$0.622^{\star \star \star}$

(0.0298)

Yes

Yes

No

30,147

0.208
(4)

0.0870 *

(0.0501)

$-0.0727^{*}$

(0.0425)

$-0.00437$

(0.0376)

$-0.0692^{*}$

(0.0390)

$-0.00869$

(0.0328)

$0.0870^{\text {*** }}$

(0.0324)

0.0307

(0.0263)

$-0.0181$

(0.0251)

0.0569 *

(0.0333)

$-0.0217$

(0.0290)

0.00719

(0.0276)

-0.159 ***

(0.0210)

$-0.139 * \star *$

(0.0251)

$-0.0543^{\text {** }}$

(0.0214)

$-0.0397^{*}$

(0.0225)

$0.587^{\text {*** }}$

(0.0417)

Yes

Yes

Yes

30,112

0.209

Notes: * $p<0.1 ;{ }^{* *} p<0.05 ;{ }^{* *} p<0.01$. Standard errors clustered by village ID are in parentheses. The demographic, socio-economic, and village controls are the same as those shown in Table 2. The "Long Distance" Variable is a binary indicator for whether a village is at or above the median distance to a secondary school (equal to greater than $3 \mathrm{~km}$ away) 
Table 6: Heterogeneous Effects of Exposure to the Cycle Program on Girls' Enrollment in Secondary School

\section{Covariates}

Treatment group $=$ Age 14 and 15

Control group $=$ Age 16 and 17

Treat×FemalexBihar×Covariate

Treat $\times$ Female $\times$ Covariate

Treat×Female $\times$ Bihar

Female $\times$ Bihar $\times$ Covariate

Treat $\times$ Bihar $\times$ Covariate

Constant

$\mathrm{HH} \&$ socio-economic controls

Village level controls

Full Sample

Only Includes Villages => 3km from Nearest School

Observations

R-squared

\section{Asset Index}

SES Index

OBC vs. General

(1)
(3)

(4)

\begin{tabular}{|c|c|c|c|c|c|c|c|c|c|c|c|}
\hline $\begin{array}{l}0.00573 \\
(0.0239)\end{array}$ & $\begin{array}{c}0.0424 \\
(0.0348)\end{array}$ & $\begin{array}{c}0.0144 \\
(0.0183)\end{array}$ & $\begin{array}{c}0.0133 \\
(0.0254)\end{array}$ & $\begin{array}{c}0.0485 \\
(0.0818)\end{array}$ & $\begin{array}{r}-0.0241 \\
(0.103)\end{array}$ & $\begin{array}{l}-0.0393 \\
(0.0935)\end{array}$ & $\begin{array}{r}-0.0886 \\
(0.119)\end{array}$ & $\begin{array}{r}-0.0522 \\
(0.114)\end{array}$ & $\begin{array}{c}-0.162 \\
(0.131)\end{array}$ & $\begin{array}{l}0.0564 \\
(0.106)\end{array}$ & $\begin{array}{l}0.0231 \\
(0.136)\end{array}$ \\
\hline $\begin{array}{c}0.0153 \\
(0.0200)\end{array}$ & $\begin{array}{r}-0.00830 \\
(0.0289)\end{array}$ & $\begin{array}{l}0.00484 \\
(0.0157)\end{array}$ & $\begin{array}{l}0.00783 \\
(0.0220)\end{array}$ & $\begin{array}{l}-0.0479 \\
(0.0729)\end{array}$ & (0.09 & $\begin{array}{c}0.0327 \\
(0.0835)\end{array}$ & & & $\begin{array}{l}-0.00441 \\
(0.0933)\end{array}$ & $\begin{array}{l}-0.0315 \\
(0.0936)\end{array}$ & (0.119) \\
\hline $\begin{array}{l}0.0820 * \star \star \\
(0.0277)\end{array}$ & $\begin{array}{l}0.117^{\star \star \star} \\
(0.0375)\end{array}$ & $\begin{array}{c}0.0791 * * * \\
(0.0306)\end{array}$ & $\begin{array}{l}0.114^{\star \star *} \\
(0.0414)\end{array}$ & $\begin{array}{c}0.0284 \\
(0.0765)\end{array}$ & $\begin{array}{c}0.119 \\
(0.0977)\end{array}$ & $\begin{array}{c}0.0296 \\
(0.0769)\end{array}$ & $\begin{array}{c}0.118 \\
(0.0987)\end{array}$ & $\begin{array}{c}0.0274 \\
(0.0769)\end{array}$ & $\begin{array}{r}0.1 \\
(0.05\end{array}$ & $\begin{array}{l}17 \\
67)\end{array}$ & $\begin{array}{l}0.0862 \\
(0.110)\end{array}$ \\
\hline$(0.0174)$ & $\begin{array}{l}-0.0296 \\
(0.0252)\end{array}$ & $\begin{array}{l}-0.0162 \\
(0.0145)\end{array}$ & $\begin{array}{l}-0.0108 \\
(0.0202)\end{array}$ & $\begin{array}{c}0.0162 \\
(0.0786)\end{array}$ & $\begin{array}{l}0.0949 \\
(0.108)\end{array}$ & $\begin{array}{c}0.0546 \\
(0.0877)\end{array}$ & $\begin{array}{c}0.115 \\
(0.118)\end{array}$ & $\begin{array}{l}-0.0188 \\
(0.0990)\end{array}$ & $\begin{array}{l}0.0744 \\
(0.129)\end{array}$ & $\begin{array}{c}0.0802 \\
(0.0998)\end{array}$ & $\begin{array}{l}0.0834 \\
(0.137)\end{array}$ \\
\hline $\begin{array}{l}-0.00545 \\
(0.0150)\end{array}$ & $\begin{array}{l}-0.0291 \\
(0.0213)\end{array}$ & $\begin{array}{c}-0.00705 \\
(0.0114)\end{array}$ & $\begin{array}{l}-0.0114 \\
(0.0150)\end{array}$ & $\begin{array}{l}-0.0656 \\
(0.0500)\end{array}$ & $\begin{array}{c}0.0284 \\
(0.0648)\end{array}$ & $\begin{array}{c}0.0130 \\
(0.0591)\end{array}$ & $\begin{array}{c}0.0709 \\
(0.0765)\end{array}$ & $\begin{array}{c}0.0287 \\
(0.0813)\end{array}$ & $\begin{array}{c}0.137 \\
(0.0948)\end{array}$ & $\begin{array}{c}-0.0394 \\
(0.0649)\end{array}$ & $\begin{array}{c}0.0387 \\
(0.0828)\end{array}$ \\
\hline $\begin{array}{l}0.470 \star \star \star \\
(0.0117)\end{array}$ & $\begin{array}{l}0.454^{\star \star \star} \\
(0.0146)\end{array}$ & $\begin{array}{l}0.499 * \star \star \\
(0.0124)\end{array}$ & $\begin{array}{l}0.475^{\star \star \star} \\
(0.0158)\end{array}$ & $\begin{array}{l}0.530 * \star \star \\
(0.0554)\end{array}$ & $\begin{array}{l}0.432 * \star \star \\
(0.0751)\end{array}$ & $\begin{array}{l}0.524 * \star \star \\
(0.0648)\end{array}$ & $\begin{array}{l}0.421^{\star \star *} \\
(0.0912)\end{array}$ & $\begin{array}{l}0.447^{\star \star *} \\
(0.0693)\end{array}$ & $\begin{array}{l}0.323^{\star \star \star} \\
(0.0905)\end{array}$ & $\begin{array}{l}0.559 * \star \star \\
(0.0696)\end{array}$ & $\begin{array}{l}0.434^{\star \star \star} \\
(0.0909)\end{array}$ \\
\hline
\end{tabular}

$\begin{array}{ccccccccccccc}\text { No } & \text { No } & \text { No } & \text { No } & \text { Yes } & \text { Yes } & \text { Yes } & \text { Yes } & \text { Yes } & \text { Yes } & \text { Yes } \\ \text { No } & \text { No } & \text { No } & \text { No } & \text { Yes } & \text { Yes } & \text { Yes } & \text { Yes } & \text { Yes } & \text { Yes } & \text { Yes } \\ \text { Yes } & \text { No } & \text { Yes } & \text { No } & \text { Yes } & \text { No } & \text { Yes } & \text { No } & \text { Yes } & \text { No } & \text { Yes } & \text { No } \\ \text { No } & \text { Yes } & \text { No } & \text { Yes } & \text { No } & \text { Yes } & \text { No } & \text { Yes } & \text { No } & \text { Yes } & \text { No } & \text { Yes } \\ 30,148 & 17,037 & 30,147 & 17,036 & 20,327 & 10,844 & 9,677 & 5,181 & 9,223 & 5,786 & 7,435 & 4,024 \\ 0.119 & 0.110 & 0.089 & 0.088 & 0.206 & 0.191 & 0.256 & 0.246 & 0.229 & 0.217 & 0.298 & 0.299\end{array}$

Notes: * $p<0.1 ; * \star p<0.05 ; * \star * p<0.01$. Standard errors clustered by village ID are in parentheses. The summary statistics for the demographic, and socio-economic are shown in

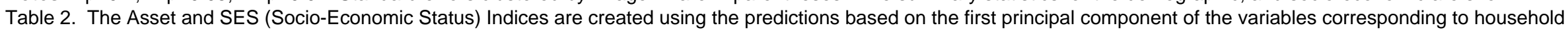
assets and SES indicators indicated in Table 1. The odd columns report the regressions from the full sample, while the even numbered columns report the regressions from the sub-sample when the secondary school is at or above the median distance to a secondary school (equal to greater than $3 \mathrm{~km}$ away) 
Table 7: Impact of Exposure to the Cycle Program on Girls' Appearance in and Performance on Grade 10 Board Exams

\begin{tabular}{|c|c|c|c|c|}
\hline \multirow[t]{4}{*}{ Dependent Variable } & $\begin{array}{l}\text { Log (Number of Candidates who } \\
\text { Appeared for the 10th Grade Exam) }\end{array}$ & $\begin{array}{c}\text { Log (Number of Candidates who Passed } \\
\text { the 10th Grade Exam) }\end{array}$ & $\begin{array}{l}\text { Log (Number of Candidates who } \\
\text { Appeared for the 10th Grade Exam) }\end{array}$ & $\begin{array}{l}\text { Log (Number of Candidates who } \\
\text { Passed the 10th Grade Exam) }\end{array}$ \\
\hline & \multicolumn{4}{|c|}{ Triple Difference (DDD) Estimate of Exposure to Cycle Program } \\
\hline & \multicolumn{2}{|c|}{ School Level } & \multicolumn{2}{|c|}{ District Level } \\
\hline & (1) & (2) & (3) & (4) \\
\hline Bihar Dummy $\times$ FemalexPost & $\begin{array}{l}0.0946^{\star *} \\
(0.0441)\end{array}$ & $\begin{array}{l}0.00103 \\
(0.0459)\end{array}$ & $\begin{array}{c}0.112 \\
(0.247)\end{array}$ & $\begin{array}{l}0.0427 \\
(0.259)\end{array}$ \\
\hline Female×Bihar Dummy & $\begin{array}{l}-0.230^{\star \star \star} \\
(0.0292)\end{array}$ & $\begin{array}{l}-0.183^{\star \star \star} \\
(0.0306)\end{array}$ & $\begin{array}{l}-0.216 \\
(0.162)\end{array}$ & $\begin{array}{l}-0.188 \\
(0.169)\end{array}$ \\
\hline Bihar $\times$ Post & $\begin{array}{l}0.440^{\star \star \star} \\
(0.0312)\end{array}$ & $\begin{array}{l}0.348^{\star \star *} \\
(0.0320)\end{array}$ & $\begin{array}{l}-0.0508 \\
(0.169)\end{array}$ & $\begin{array}{l}-0.108 \\
(0.178)\end{array}$ \\
\hline FemalexPost & $\begin{array}{l}0.209^{\star \star \star} \\
(0.0383)\end{array}$ & $\begin{array}{l}0.214^{\star \star \star} \\
(0.0395)\end{array}$ & $\begin{array}{l}0.194 \\
(0.207)\end{array}$ & $\begin{array}{l}0.186 \\
(0.215)\end{array}$ \\
\hline Female Dummy & $\begin{array}{l}-0.661^{\star \star \star} \\
(0.0261)\end{array}$ & $\begin{array}{l}-0.732^{\star \star \star} \\
(0.0273)\end{array}$ & $\begin{array}{l}-0.504^{\star \star \star} \\
(0.140)\end{array}$ & $\begin{array}{l}-0.551^{\star \star \star} \\
(0.145)\end{array}$ \\
\hline Bihar Dummy & $\begin{array}{l}0.221^{\star \star *} \\
(0.0203)\end{array}$ & $\begin{array}{l}0.185^{\star \star *} \\
(0.0209)\end{array}$ & $\begin{array}{c}0.511^{\star * \star} \\
(0.110)\end{array}$ & $\begin{array}{c}0.501^{* \star *} \\
(0.114)\end{array}$ \\
\hline Post & $\begin{array}{l}-0.0823^{\star \star \star} \\
(0.0278)\end{array}$ & $\begin{array}{l}-0.113^{\star \star *} \\
(0.0283)\end{array}$ & $\begin{array}{c}0.425^{\star \star \star} \\
(0.143)\end{array}$ & $\begin{array}{l}0.358^{\star *} \\
(0.150)\end{array}$ \\
\hline Constant & $\begin{array}{l}4.484^{\star \star \star} \\
(0.0184)\end{array}$ & $\begin{array}{l}4.241^{\star \star *} \\
(0.0189)\end{array}$ & $\begin{array}{l}8.523^{\star \star \star} \\
(0.0957)\end{array}$ & $\begin{array}{l}8.274^{\star \star \star} \\
(0.0989)\end{array}$ \\
\hline Observations & 45,564 & 45,215 & 676 & 676 \\
\hline R-squared & 0.162 & 0.144 & 0.255 & 0.214 \\
\hline
\end{tabular}

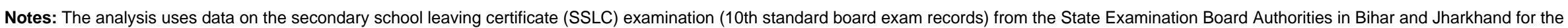
years 2004 - 2010. The data on the number of students who appeared in and passed the exams are at the school level in columns 1 and 2 and at the district level in columns 3 and 4 , with each observation

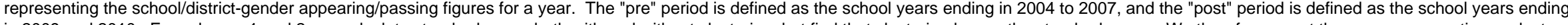

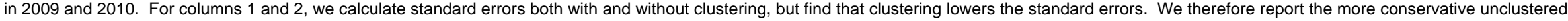
standard errors. * $p<0.1$; $* \star p<0.05 ; * \star * ~ p<0.01$ 
Table 8: Triple Difference (DDD) Estimate of the Impact of Being Exposed to the Cycle Program on Girl's Enrollment in Eighth Grade (Placebo Test)

\section{Treatment group $=$ Age 13 and 14 \\ Control group = Age 15 and 16}

Treat×Female dummy×Bihar dummy

Treat×Female dummy

Treat×Bihar dummy

Female dummy×Bihar dummy

Treat

Female dummy

Bihar dummy

Constant

Demographic controls

$\mathrm{HH}$ socio-economic controls

Village level controls

Observations

R-squared
Dependent variable: Enrolled in or completed grade 8

0.0111
$(0.0237)$

$-0.00226$

(0.0229)

0.0259

$0.0384^{\star *}$

(0.0178)

$-0.00699$

(0.0180)

(0.0184)

-0.0350 **

(0.0176)

(0.0184)

$-0.155^{\star \star \star}$

(0.0149)

(0.0152)

-0.0950 ***

(0.0141)

(0.0148)

$-0.105^{\star \star *}$

(0.0167)

(0.0159)

$0.818^{\star \star *}$

$0.522^{\text {** }}$

(0.0131)

(0.0243)

$\begin{array}{cc}\text { No } & \text { Yes } \\ \text { No } & \text { No } \\ \text { No } & \text { No } \\ 33,179 & 33,179 \\ 0.038 & 0.089\end{array}$

0.000779

(0.0215)

$0.0475^{\star \star \star}$

(0.0170)

$-0.00813$

(0.0163)

$-0.0351^{\star *}$

(0.0169)

$-0.156^{\star \star \star}$

(0.0133)

$-0.103^{\star \star \star}$

(0.0138)

$-0.0852^{\star \star \star}$

(0.0142)

$0.644^{\star \star *}$

(0.0266)

Yes

Yes

No

33,012

0.201
0.000263

(0.0215)

$0.0471^{\text {*** }}$

$-0.00796$

(0.0164)

$-0.0338^{* *}$

(0.0169)

$-0.156^{\star \star \star}$

(0.0133)

$-0.103^{\star \star *}$

(0.0138)

-0.0960 ***

(0.0148)

$0.635^{\star \star \star}$

(0.0378)

Yes

Yes

Yes

32,972

0.202

Notes: ${ }^{\star} p<0.1 ;{ }^{* \star} p<0.05 ;{ }^{* \star \star} p<0.01$. Standard errors clustered by village ID are in parentheses. Unlike Table 4 that uses an estimation sample of household residents aged 14-17, this table uses household residents aged 13-16 as the estimation sample because we are interested in age-appropriate enrollment rates in grade 8 as opposed to grade 9. The demographic, socioeconomic, and village controls are the same as those shown in Table 2 


\title{
Table 9: Triple Difference (DDD) Estimate of the Impact of Being Exposed to the Cycle Program on Girl's Secondary School Enrollment (Border Districts Only)
}

\author{
Treatment group $=$ Age 14 and 15 \\ Control group $=$ Age 16 and 17 \\ Treat $\times$ Female dummy×Bihar dummy \\ $(1)$ \\ (2) \\ (3) \\ $0.0985^{\star *}$ \\ $0.0946^{* *}$ \\ 0.0584 \\ 0.0553 \\ (0.0407) \\ (0.0385) \\ (0.0356) \\ (0.0356) \\ Treat $\times$ Female dummy \\ 0.0400 \\ $0.0412^{*}$ \\ $0.0487^{\text {** }}$ \\ $0.0485^{\star \star}$ \\ (0.0267) \\ (0.0242) \\ (0.0231) \\ (0.0232) \\ Treat×Bihar dummy \\ $-0.0683^{\star \star}$ \\ -0.0740 *夫 \\ $-0.0717^{\star \star \star *}$ \\ $-0.0688^{\star \star}$ \\ (0.0295) \\ (0.0288) \\ (0.0267) \\ (0.0267) \\ Female dummy $\times$ Bihar dummy \\ $-0.0876^{\star \star \star}$ \\ $-0.0945^{\star \star \star}$ \\ $-0.0605^{\star \star}$ \\ (0.0338) \\ (0.0320) \\ (0.0294) \\ $-0.0577^{*}$ \\ $-0.154^{\star \star \star}$ \\ $-0.146^{\star \star \star}$ \\ $-0.138^{\star \star \star}$ \\ (0.0294) \\ Treat \\ (0.0177) \\ (0.0167) \\ (0.0158) \\ $-0.139 * \star \star$ \\ (0.0158) \\ Female dummy \\ $-0.115^{\star \star \star}$ \\ $-0.108^{\star \star \star}$ \\ $-0.118^{\star \star \star}$

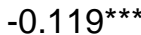 \\ (0.0233) \\ (0.0218) \\ (0.0215) \\ Bihar dummy \\ 0.0195 \\ $-0.0152$ \\ (0.0213) \\ $-0.0149$ \\ (0.0288) \\ (0.0277) \\ $-0.00315$ \\ (0.0232) \\ Constant \\ 0.449 *** \\ $0.612^{\star \star \star}$ \\ (0.0235) \\ $0.367^{\star \star \star}$ \\ (0.0185) \\ (0.0411) \\ Demographic controls \\ $\mathrm{HH}$ socio-economic controls \\ No \\ No \\ Yes \\ Village level controls \\ Border Districts Only \\ No \\ Yes \\ No \\ No \\ Yes \\ $0.455^{\star \star \star}$ \\ (0.0614) \\ 9,939 \\ 9,939 \\ 0.040 \\ 0.093 \\ (0.0451) \\ Yes \\ Yes \\ Yes \\ Yes \\ R-squared \\ Yes \\ Yes \\ No \\ Yes \\ 9,886 \\ 9,899 \\ 0.223 \\ Notes: ${ }^{*} p<0.1 ;{ }^{* \star} p<0.05 ;{ }^{* \star *} p<0.01$. Standard errors clustered by village ID are in parentheses. The \\ demographic, socio-economic, and village controls are the same as those shown in Table 2 \\ Bihar Border Districts: Katihar, Bhagalpur, Banka, Rohtas, Aurangabad, Gaya, Nawada, Jamui \\ Jharkhand Border Districts: Garawah, Palamu, Chatra, Hazaribagh, Kodarma, Giridih, Deoghar, Godda, \\ Sahibganj, Dumka
}


Figure 1

Panel A: Enrollment in School by Age and Gender
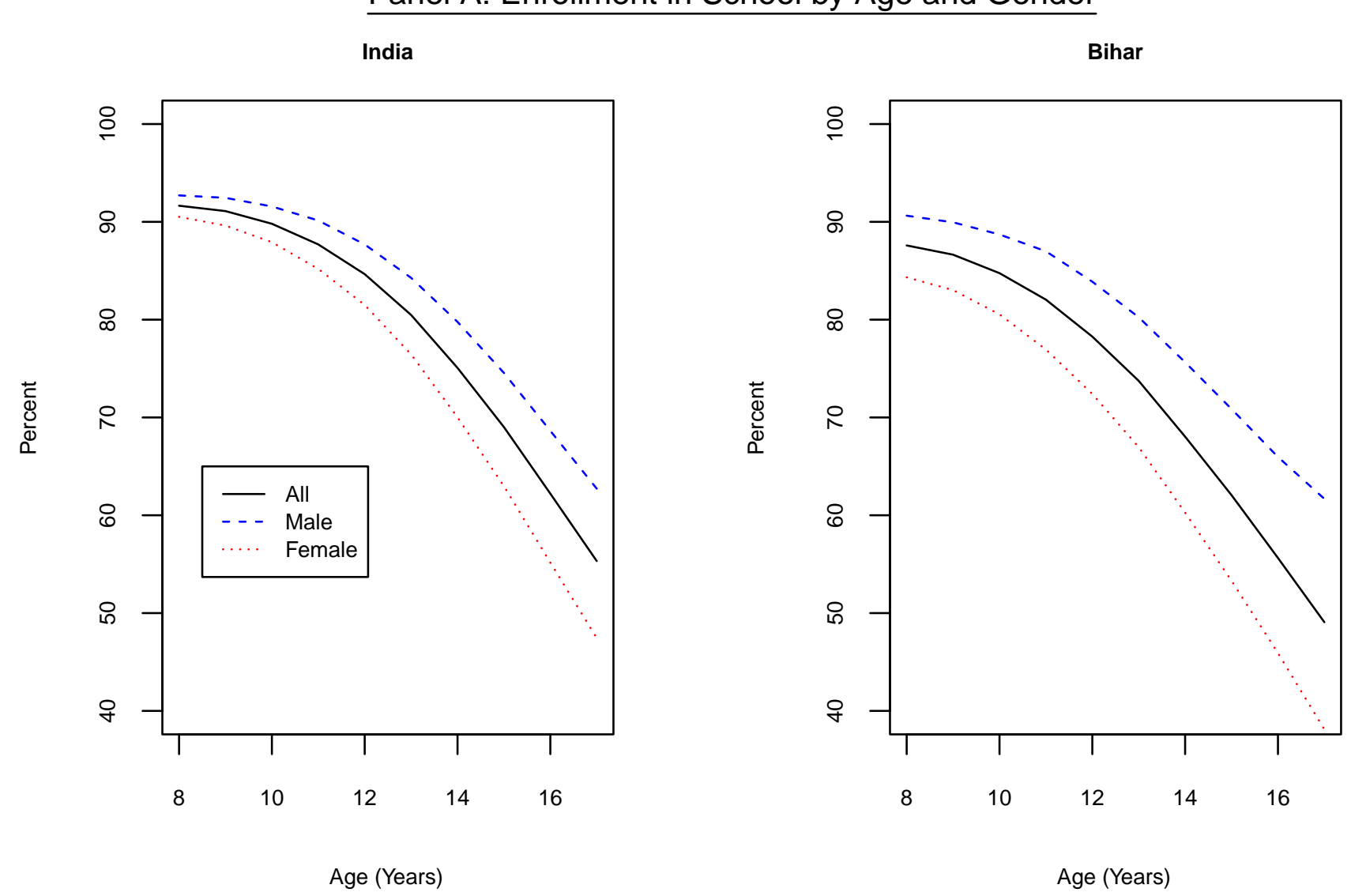

Source: Author's calculations using the 2008 District Level Health Survey (DLHS).

Panel B: Enrollment in Secondary School of 14 and 15 Year Olds by Distance and Gender

India

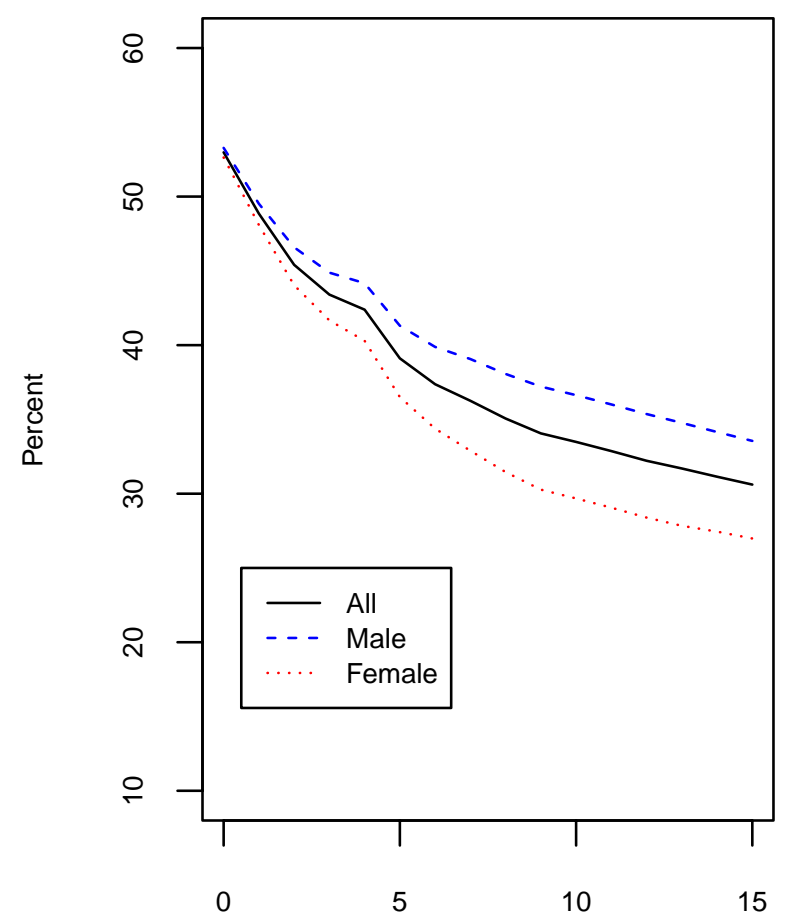

Distance to Secondary School (KM)
Bihar

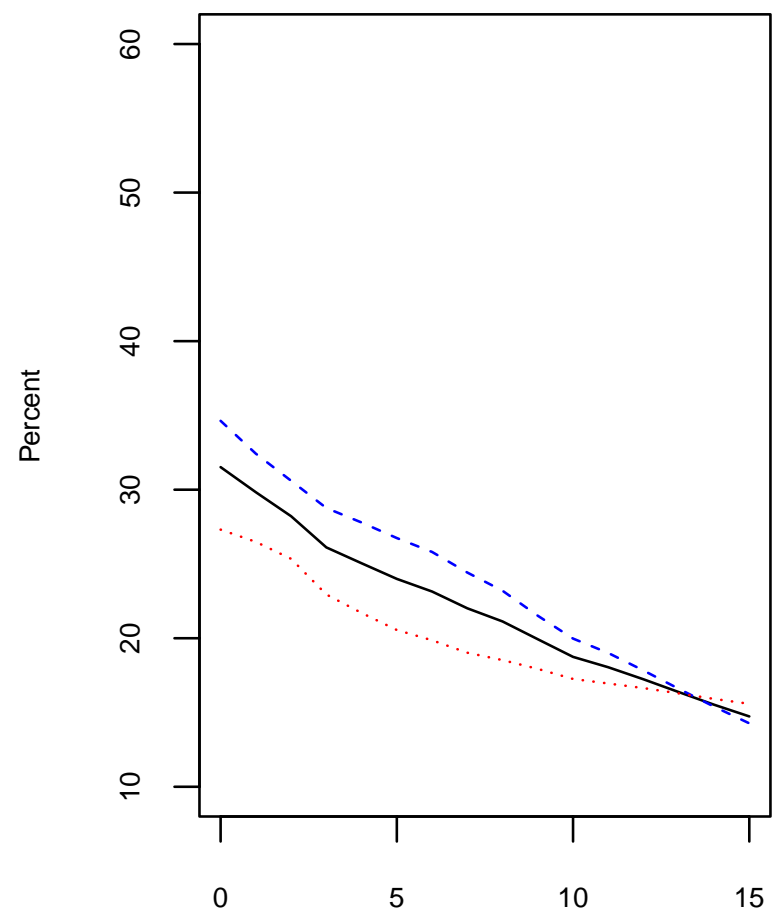

Distance to Secondary School (KM) 
Figure 2: Distribution of Villages by Distance to Nearest Secondary School
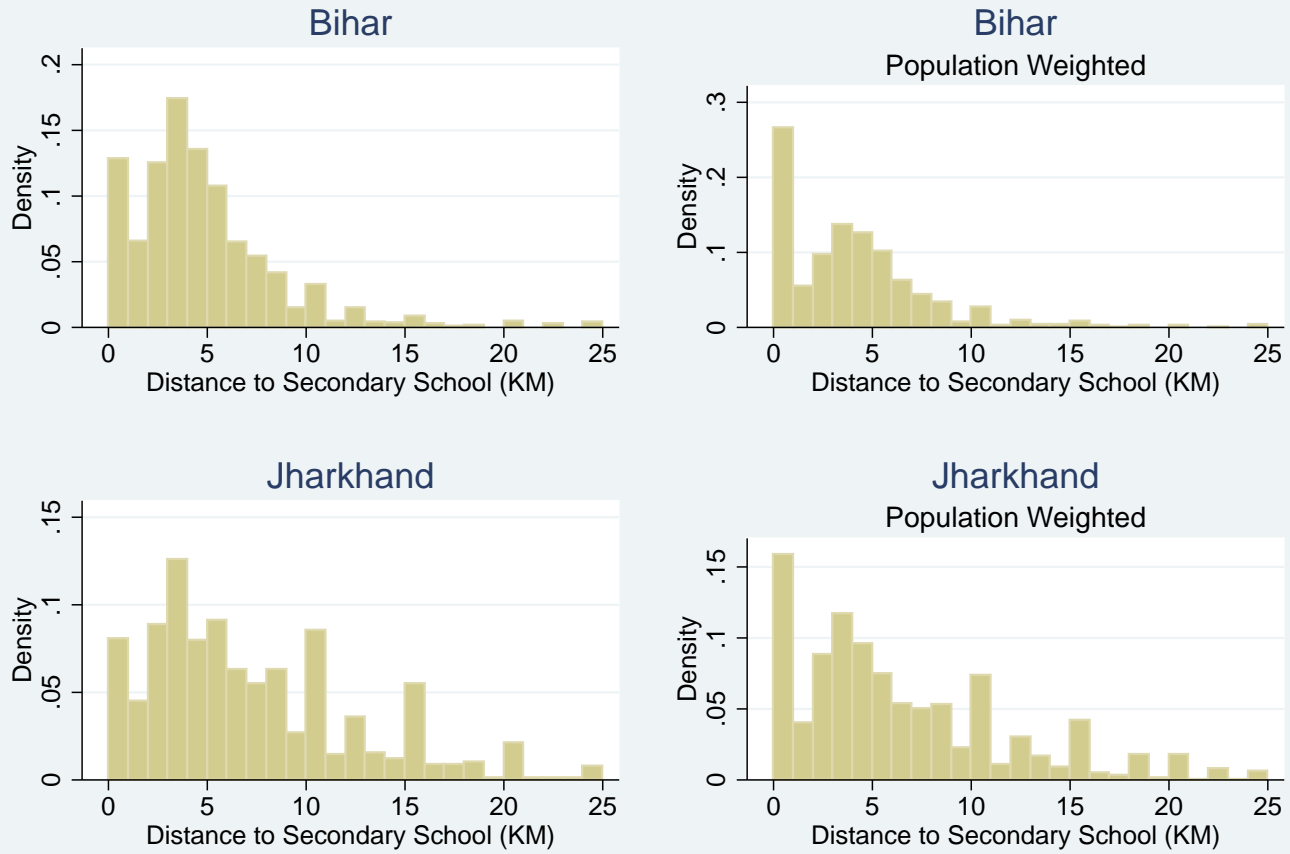


\section{Figure 3: Simple Sketch of Mechanism of Impact of Cycle Program}

\section{Cost/Benefit of Going}

to Secondary School

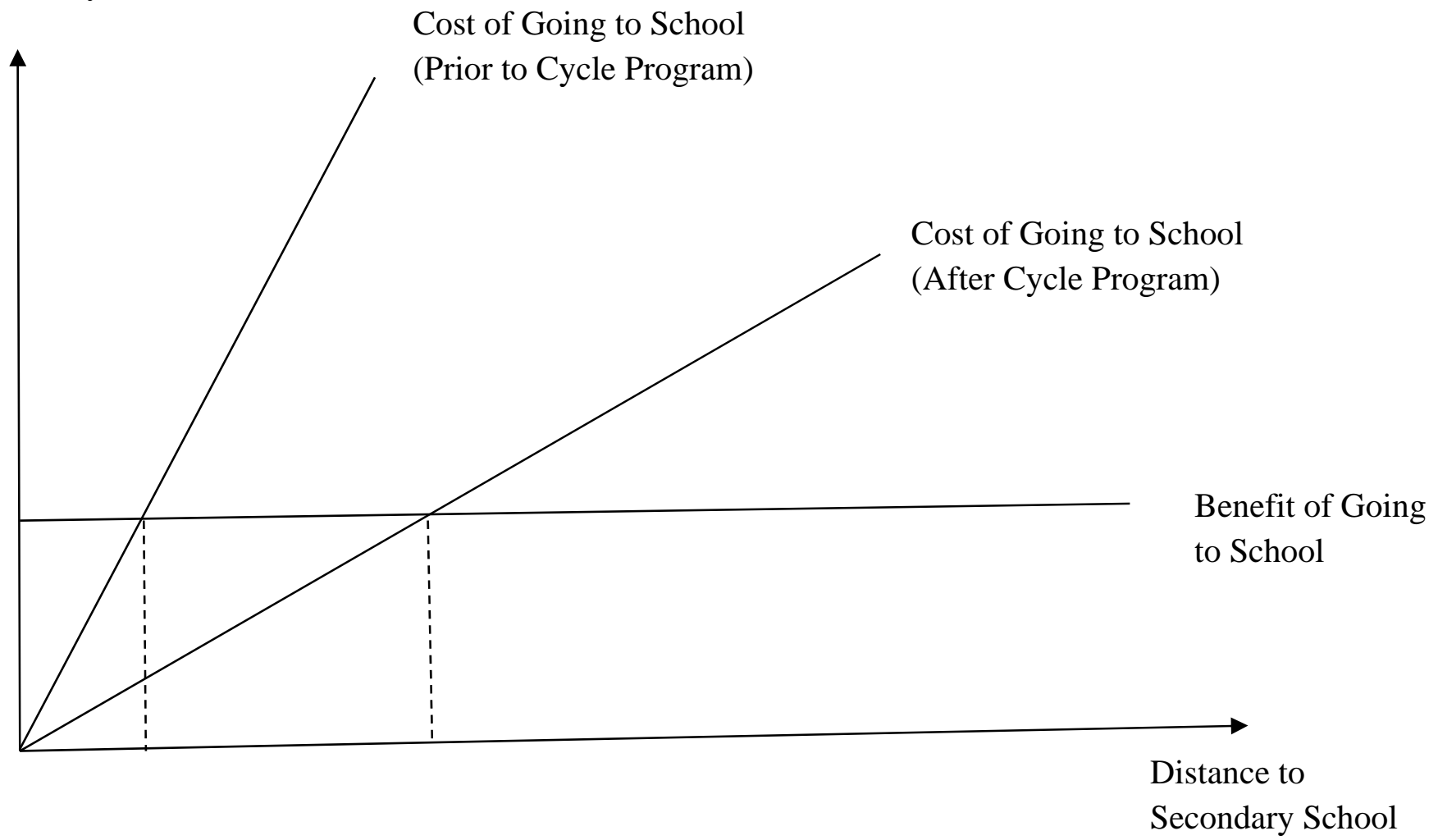


Figure 4: Non-parametric double and triple difference estimates of impact of the cycle program (by distance to nearest secondary school)

\section{Panel A: Bihar Double Difference by Distance to Secondary School}

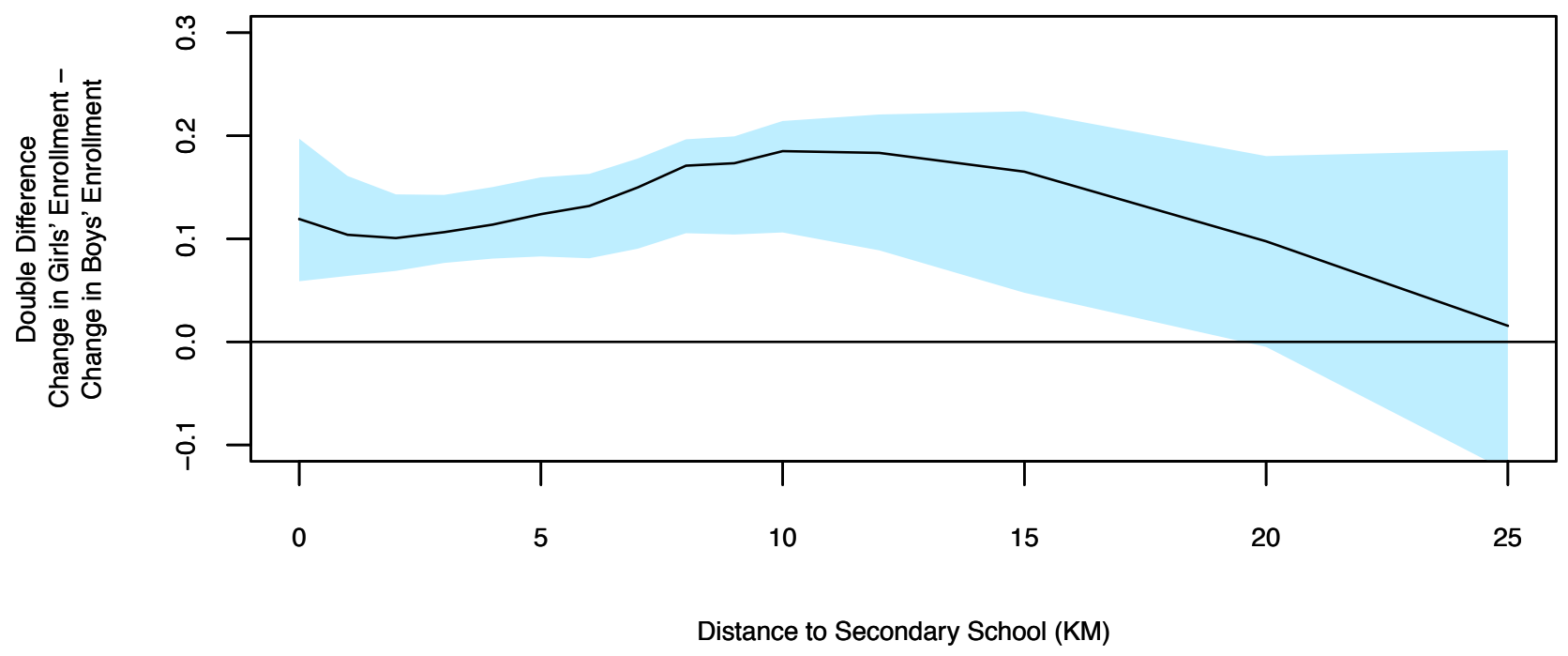

Panel B: Jharkhand Double Difference by Distance to Secondary School

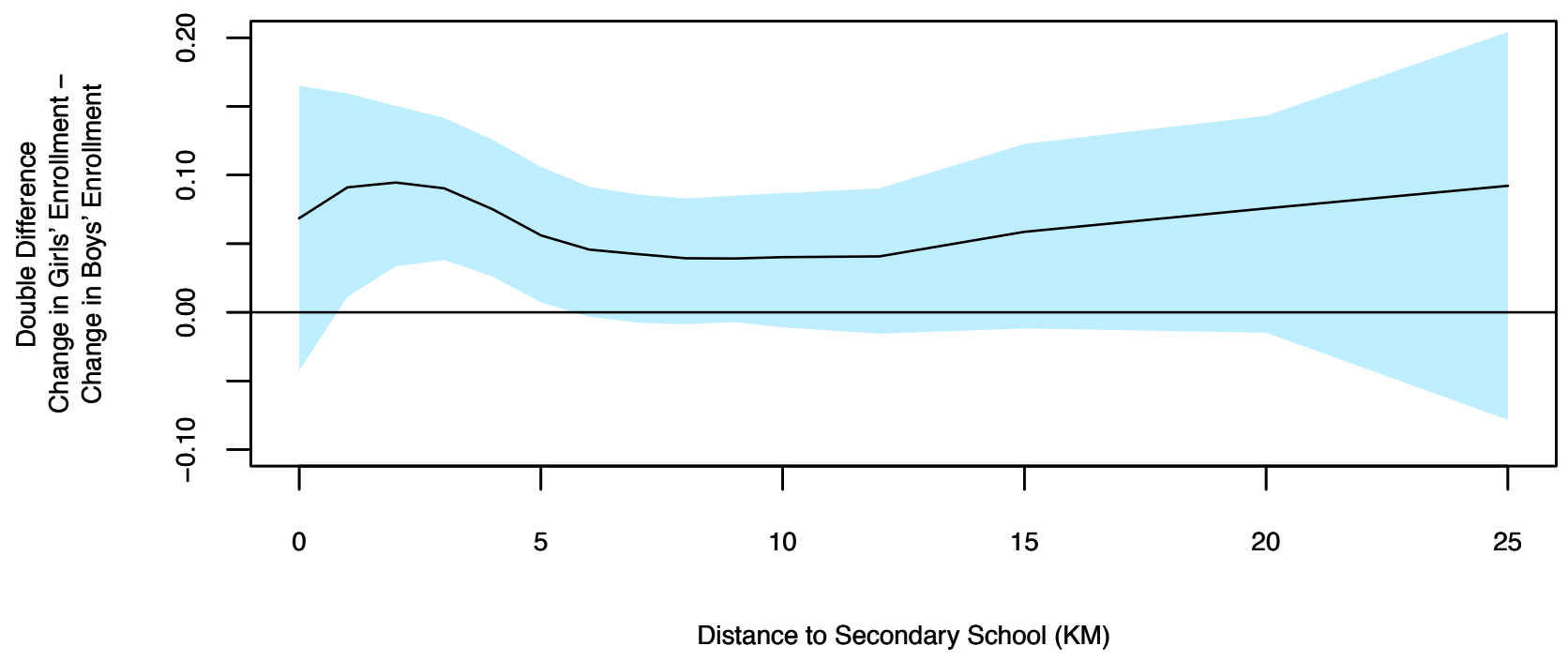

Panel C: Triple Difference by Distance to Secondary School

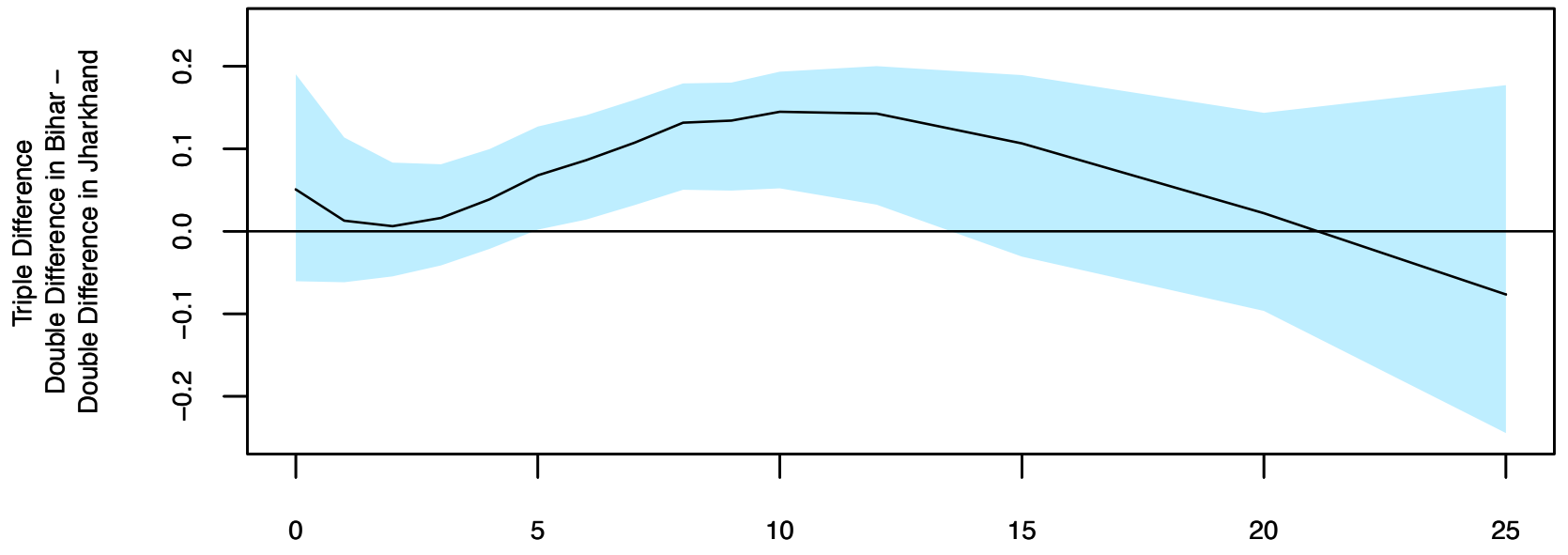

